\title{
New Ground Motion to Intensity Conversion Equations for China
}

\author{
Xiufeng Tian $\mathbb{D}^{1,2}$ Zengping Wen, ${ }^{1}$ Weidong Zhang, ${ }^{2}$ and Jie Yuan ${ }^{2}$ \\ ${ }^{1}$ Institute of Geophysics, China Earthquake Administration, Beijing 10081, China \\ ${ }^{2}$ Gansu Earthquake Agency, Lanzhou 73000, Gansu, China \\ Correspondence should be addressed to Xiufeng Tian; txf913@163.com
}

Received 18 February 2021; Revised 28 June 2021; Accepted 21 July 2021; Published 29 July 2021

Academic Editor: Sara Amoroso

Copyright (C) 2021 Xiufeng Tian et al. This is an open access article distributed under the Creative Commons Attribution License, which permits unrestricted use, distribution, and reproduction in any medium, provided the original work is properly cited.

In this study, we use the strong motion records and seismic intensity data from 11 moderate-to-strong earthquakes in the mainland of China since 2008 to develop new conversion equations between seismic intensity and peak ground motion parameters. Based on the analysis of the distribution of the dataset, the reversible conversion relationships between modified Mercalli intensity (MMI) and peak ground acceleration (PGA), peak ground velocity (PGV), and pseudo-spectral acceleration (PSA) at natural vibration periods of $0.3 \mathrm{~s}, 1.0 \mathrm{~s}, 2.0 \mathrm{~s}$, and $3.0 \mathrm{~s}$ are obtained by using the orthogonal regression. The influence of moment magnitude, hypocentral distance, and hypocentral depth on the residuals of conversion equations is also explored. To account for and eliminate the trends in the residuals, we introduce a magnitude-distance-depth correction term and obtain the improved relationships. Furthermore, we compare the results of this study with previously published works and analyze the regional dependence of conversion equations. To quantify the regional variations, a regional correction factor for China, suitable for adjustment of global relationships, has also been estimated.

\section{Introduction}

As a qualitative index to describe the ground vibration and degree of damage caused by an earthquake, the seismic intensity provides a simple macroscopic scale to characterize the magnitude of an earthquake's impact on human communities, so it is widely used in earthquake disaster assessment, loss estimation, structural response analyses, historical earthquake disaster recurrence, and other fields all over the world [1]. Traditionally, seismic intensity is typically obtained by experts who investigate the building damage and human response to an earthquake in an area where that earthquake strikes. Ground motion parameters, such as PGA, PGV, and PSA, which are used as quantitative indexes to describe the degree of ground vibration, are usually obtained from the records of seismic observation instruments deployed in earthquake areas. How to transform the ground motion parameters into seismic intensity and establish the conversion equation between them is of great significance for the rapid assessment of earthquake disaster and loss (such as the generation of ShakeMap [2]), the comparative analysis of different types of intensity scales, and other engineering applications.
In some countries or regions with abundant seismic records (e.g., the United States, Japan, Italy, Turkey, New Zealand, and Taiwan), researchers have explored the correlation between seismic intensity and ground motion parameters and established the corresponding ground motion to intensity conversion equations (GMICEs) [3-12]. At present, there are numerous seismic intensity scales, such as modified Mercalli intensity (MMI), Mercalli-Cancani-Sieberg (MCS) intensity, JMA intensity in Japan, and so on in which MMI is the most widely used. With respect to these seismic intensity scales, most researchers calibrate their conversion equations using PGA, PGV, and PSA as physical indicators. In early works, PGA was employed as the ground motion parameter that would provide accurate seismic intensity estimates because it was assumed that the product of acceleration and mass would accurately characterize the inertial forces acting on the structure [13-15]. However, because PGV is directly related to the kinetic energy, some studies have found that the correlation between PGV and seismic intensity is stronger than it is for PGA $[16,17]$. Wald et al. proposed that low seismic intensities were strongly correlated to both PGA and PGV, while high seismic 
intensities were only strongly correlated with PGV [3]. Bilal and Askan concluded that the seismic intensity was more closely related to PGV for ductile structures and PGA for brittle structures [8]. For the response spectrum parameters, which are directly related to the seismic response and structural damage, many researchers found that they were also closely related to seismic intensity. As Spence et al. demonstrated, the correlation between seismic intensity and PSA (5\% damping ratio) over a period of $0.1 \mathrm{~s}$ to $0.3 \mathrm{~s}$ was stronger than it is for PGA [18]. Boatwright et al. determined that seismic intensity correlated best with the velocity response spectra ( $5 \%$ damping ratio) at a period of $1.5 \mathrm{~s}$ [19]. In addition, Caprio et al. derived new global relationships, assembling a database from active crustal regions in California, Italy, Greece, and global data from the Central and Eastern United States catalog. The authors obtained the PGA and PGV to intensity conversion equations and provided regional correction factors to the global relationships for Italy, Greece, and California, as well as a regional similarity study for other regions of the world [10]. Moratalla et al. considered a large amount of data derived from New Zealand earthquakes and developed the updated GMICEs between MMI and PGA/PGV [11]. The work also proposed a regional correction factor for New Zealand, suitable for the global relationships of Caprio et al. [10].

The research on the correlation between seismic intensity and ground motion parameters in China began in the 1960s. The intensity scale used was MMI, and the PGA value corresponding to the intensity of VII-IX was given in the seismic building design code at that time. Due to the lack of local strong motion records in China, Liu et al. used a small amount of seismic data from the United States and some foreign research results [20], took PGA and PGV as the measures of seismic intensity, and gave the conversion equations between MMI and PGA/PGV [21], which were applied in Chinese seismic intensity scale in 1980 . Du et al. derived a new empirical relationship between MMI and PGA/PGV for Western China, using the ground motion records of earthquakes that occurred before 2014 [22]. The work used a weighted least-squares regression method, resulting in an irreversible conversion from PGA/PGV to MMI, and the relationship between MMI and PSA was not considered in the literature. It is worth noting that the conversion equations from PGA/PGV to MMI are not scrutinized and revised by using recent local seismic data; in addition, as of now, the robust correlation relationships between MMI and PSA, which are also very useful because the spectral quantities are strong indicators of the structural response which directly influence the observed intensity values, have not been studied in detail for Chinese earthquake dataset. So, there is an urgent need to re-examine the GMICEs in China thoroughly and develop the updated relationships using the latest local seismic data and including PSA in addition to PGA and PGV. Furthermore, two realistic factors also inspire us to develop the new GMICEs. (1) Since 2008, the operation of China Digital Strong Motion Network has greatly increased the quantity and quality of the strong motion observation stations, and in recent years, the mainland of China has experienced a number of moderate-tostrong destructive earthquakes, resulting in large volumes of strong motion records and post-earthquake seismic intensity data. (2) With the rapid development of national economy, the structure of buildings, seismic resistance, and the types of earthquake damage have changed significantly, and the distribution of the peak ground motion corresponding to the seismic intensity may also change accordingly. Thus, in this study, we intend to use the recent seismic dataset of China and develop the new conversion equations between seismic intensity and PGA, PGV, and PSA.

\section{Data Source and Analysis}

2.1. Data Source. In this study, the seismic data consist of the strong motion records from 11 moderate-to-strong earthquakes $(5.9 \leq \mathrm{Mw} \leq 7.9)$ that occurred in the mainland of China from 2008 to 2019 . We downloaded the data from the China Strong Motion Network Center (see Data Availability), which used a new digital strong motion network after 2008, and obtained a large volume of strong motion data from destructive earthquakes. The locations of the 11 earthquakes as well as the spatial distribution of the strong motion stations that recorded these events are displayed in Figure 1, the detailed information of these earthquake events is given in Table 1, and the magnitude versus hypocentral distance distribution of the dataset is shown in Figure 2. We employ the method of $\mathrm{Yu}$ et al. [23] to perform baseline correction and filtering and obtain PGA, PGV, and PSA (5\% damping ratio) at natural vibration periods of $0.3 \mathrm{~s}, 1.0 \mathrm{~s}$, $2.0 \mathrm{~s}$, and $3.0 \mathrm{~s}$ of the two horizontal components for each record. The maximum value of the two horizontal components is used in the subsequent regression analysis.

The macroseismic intensity data (in terms of MMI scale) were compiled from the isoseismal maps and damage reports of the past earthquakes (see Data Availability). The isoseismal maps were obtained by detailed post-earthquake survey and site evaluations after the earthquakes at the meizoseismal areas by reconnaissance teams. All the maps and bulletins used in this paper were prepared by the China Earthquake Administration, involving the MMI range from $\mathrm{V}$ to $\mathrm{X}$. For the past earthquakes with an observed isoseismal map or a detailed earthquake damage report from which MMI values were easy to obtain, the peak ground motion corresponding to MMI can be paired straightforwardly. We assigned one MMI value for each recorded accelerogram considering the location of accelerograph stations on the isoseismal maps or considering the observed intensity value near the stations $(\leq 2 \mathrm{~km})$, and a total of 242 peak ground motion-intensity pairs were obtained.

2.2. Data Analysis. Using the seismic dataset described in the previous section, we have calculated the $\max , \min$, and mean values, as well as the standard deviations of PGA, PGV, and PSA (hereafter denoted as PGM, i.e., peak ground motion) in logarithmic scale for different intensity units ranging from $\mathrm{V}$ to $\mathrm{X}$ (Table 2). It can be seen from Table 2 that the discreteness of seismic parameters in each intensity unit is very large, but the mean value has a good positive correlation with the intensity value. We also draw the frequency distribution of the datapoints in each intensity unit 


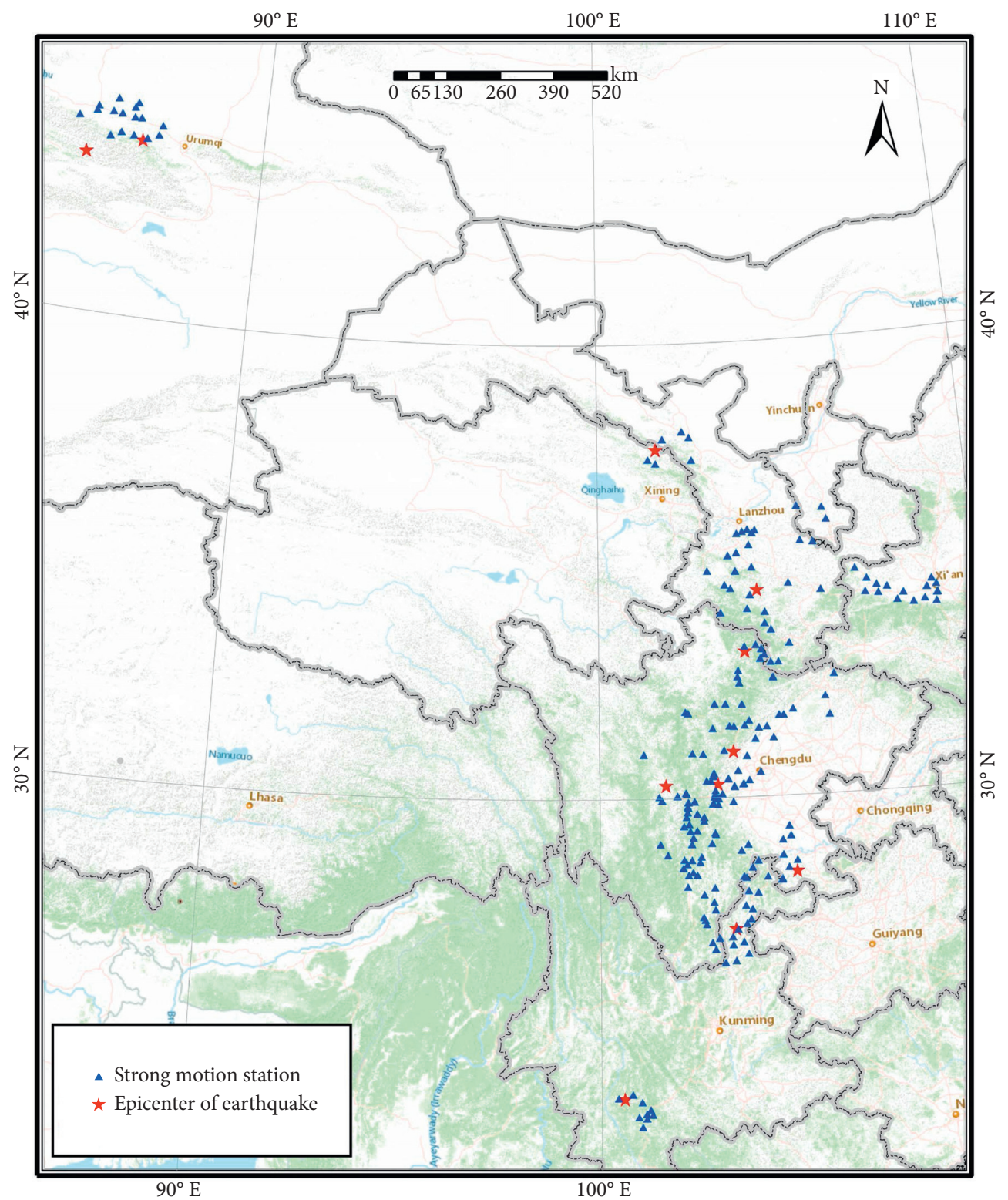

Figure 1: Locations of earthquake events and strong motion stations used in this study.

for $\log$ PGM (Figures 3 and 4, for PGA and PGV; Figures 5-8, for PSA). From these figures, we can see that the sample data in intensity units of V to VII have approximate normality, which is less obvious in the intensity units of VIII to IX due to its smaller amount of data. It also should be noted that the mode and mean values of PGA (Figure 3 ) in each intensity unit in our dataset are evidently higher than the corresponding values of Liu et al. [21]. This significant finding further illustrates the necessity to re-examine the GMICEs used in China and make necessary improvements.

In addition, the dataset in this study is also compared with the datasets of America and Turkey [2-5, 8] (Figure 9, taking PGA and PGV as examples). It can be seen from Figure 9 that the distribution of Chinese data is inconsistent with that of the other two regions. As a whole, the PGA of Chinese data in each of the intensity units is smaller than that of America and larger than that of Turkey, and the PGV of Chinese data is smaller than that of America and Turkey. This regional difference of the data distribution indicates that the GMICEs for a certain area must be obtained using the local seismic dataset, and the introduction of nonlocal seismic data may lead to inaccurate results. Therefore, only the seismic dataset of China (Table 1) is used in this study to obtain the most suitable GMICEs for local use.

\section{Regression Analysis}

3.1. Outlier Test of Data. To ensure the accuracy of the regression results, it is necessary to screen and delete outliers from our dataset prior to the statistical analyses. Because the conversion equations between MMI and PGM are usually characterized by a linear function with respect to $\log P G M$, it 
TABLE 1: List of earthquake events.

\begin{tabular}{|c|c|c|c|c|c|c|c|c|}
\hline $\begin{array}{l}\text { Serial } \\
\text { number }\end{array}$ & $\begin{array}{c}\text { Earthquake } \\
\text { name }\end{array}$ & $\begin{array}{l}\text { Event } \\
\text { date }\end{array}$ & $\begin{array}{l}\text { Latitude } \\
\qquad\left({ }^{\circ} \mathrm{N}\right)\end{array}$ & $\begin{array}{l}\text { Longitude } \\
\left({ }^{\circ} \mathrm{E}\right)\end{array}$ & $\begin{array}{l}\text { Magnitude } \\
(\mathrm{Mw})\end{array}$ & $\begin{array}{l}\text { Hypocentral } \\
\text { depth }(\mathrm{km})\end{array}$ & $\begin{array}{c}\text { Number of MMI- } \\
\text { PGA, PGV, and PSA } \\
\text { pairs }\end{array}$ & $\begin{array}{c}\text { Hypocentral } \\
\text { distance range } \\
(\mathrm{km})\end{array}$ \\
\hline 1 & Wenchuan & $\begin{array}{l}2008- \\
05-12\end{array}$ & 31.01 & 103.42 & 7.9 & 14 & 134 & $27.0-640.5$ \\
\hline 2 & Xinyuan & $\begin{array}{l}2012- \\
06-30\end{array}$ & 43.42 & 84.74 & 6.6 & 7 & 11 & $68.6-193.2$ \\
\hline 3 & Lushan & $\begin{array}{l}2013- \\
04-20\end{array}$ & 30.30 & 103.00 & 7.0 & 13 & 22 & $26.1-146.8$ \\
\hline 4 & $\begin{array}{l}\text { Minxian- } \\
\text { Zhangxian }\end{array}$ & $\begin{array}{l}2013- \\
07-22\end{array}$ & 34.54 & 104.21 & 6.6 & 15 & 13 & $26.0-112.1$ \\
\hline 5 & Ludian & $\begin{array}{l}2014- \\
08-03\end{array}$ & 27.11 & 103.33 & 6.5 & 10 & 19 & $11.2-87.4$ \\
\hline 6 & Jinggu & $\begin{array}{l}2014- \\
10-07\end{array}$ & 23.40 & 100.55 & 6.6 & 10 & 9 & $18.4-81.8$ \\
\hline 7 & Kangding & $\begin{array}{l}2014- \\
11-22\end{array}$ & 30.29 & 101.68 & 6.3 & 20 & 9 & $38.4-95.2$ \\
\hline 8 & Menyuan & $\begin{array}{l}2016- \\
01-21\end{array}$ & 37.68 & 101.62 & 6.4 & 10 & 6 & $32.1-91.0$ \\
\hline 9 & Hutubi & $\begin{array}{l}2016- \\
12-08\end{array}$ & 43.83 & 86.35 & 6.3 & 6 & 8 & $13.3-99.4$ \\
\hline 10 & Jiuzhaigou & $\begin{array}{l}2017- \\
08-08\end{array}$ & 33.20 & 103.82 & 7.0 & 20 & 8 & $32.1-110.6$ \\
\hline 11 & Changning & $\begin{array}{l}2019- \\
06-17\end{array}$ & 28.34 & 104.90 & 5.9 & 16 & 3 & $23.4-52.9$ \\
\hline
\end{tabular}

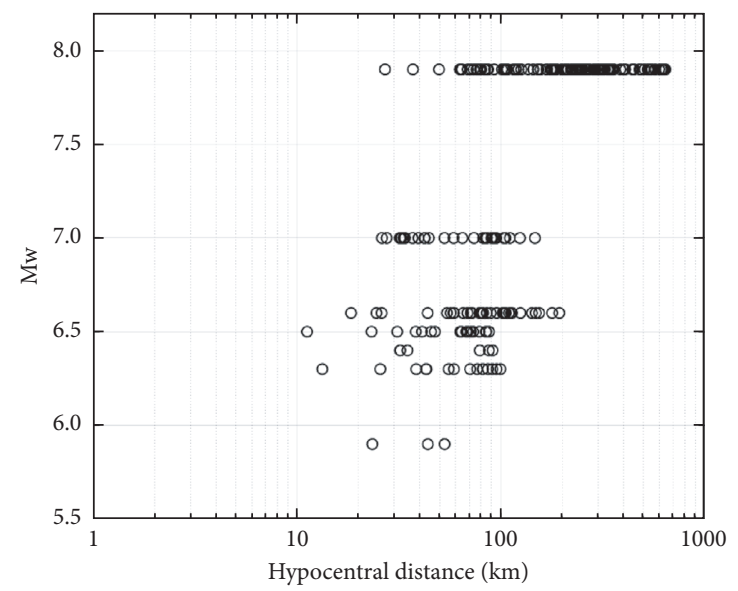

FIGURE 2: Distribution of ground motion dataset regarding magnitude and hypocentral distance.

is necessary to search for outliers in the dataset of logarithmic scale for each intensity unit.

Because the sample data of logPGM in most of the intensity units approximately obey the normal distribution, according to the recommendations in Chinese $\mathrm{Na}$ tional Standard GB/T 4883-2008 (Statistical Interpretation of Data: Detection and Treatment of Outliers in the Normal Sample) [24], we conduct the skewness-kurtosis test on sample data in intensity units ranging from $\mathrm{V}$ to VII because of the high number of samples in these intensity units. Conversely, there are fewer sample data in the intensity units of VIII and IX, and the Dixon test is used to identify the outliers. In addition, the outlier test is not performed for the intensity unit of $\mathrm{X}$ because there is only one sample data in this intensity unit.
According to the test results, we find only one straggler of $\log$ PGA value (0.38), which came from the 51BTD station located at the intensity $\mathrm{V}$ region in the 2014 Mw6.5 Ludian earthquake. This station, consisting of a MR2002/SLJ-100 seismometer, is located in Butuo County, Liangshan Prefecture, Sichuan Province. Its $\mathrm{Vs}_{30}$ is $368.12 \mathrm{~m} / \mathrm{s}$, and the observation site is the soil layer. Butuo County is built on a valley with special topography, which may lead to an abnormal PGA value that should be deleted from our dataset. It is also worth noting that the sample data of MMI X are not used in the subsequent analysis, which is because we use the mean value of the sample data in each intensity unit to develop the regression but there is only one sample data in MMI X. To avoid the fitting deviation caused by the single data and ensure the overall stability of the regression results, 
TABLE 2: Summary of statistical values for each of the intensity units.

\begin{tabular}{|c|c|c|c|c|c|c|c|c|}
\hline & MMI & $\log P G A$ & $\log P G V$ & $\log \mathrm{PSA}(0.3 \mathrm{~s})$ & $\log$ PSA $(1.0 \mathrm{~s})$ & $\log$ PSA $(2.0 \mathrm{~s})$ & $\log$ PSA $(3.0 \mathrm{~s})$ & Number of data points \\
\hline \multirow{4}{*}{$\mathrm{V}$} & Max & 2.14 & 1.31 & 2.66 & 2.08 & 2.16 & 1.93 & \multirow{4}{*}{90} \\
\hline & Min & 0.38 & -0.33 & 0.64 & 0.45 & 0.00 & -0.03 & \\
\hline & Mean & 1.40 & 0.54 & 1.74 & 1.46 & 1.32 & 1.11 & \\
\hline & St.dev & 0.28 & 0.37 & 0.32 & 0.39 & 0.48 & 0.46 & \\
\hline \multirow{4}{*}{ VI } & $\operatorname{Max}$ & 2.63 & 1.44 & 2.89 & 2.43 & 2.41 & 2.03 & \multirow{4}{*}{96} \\
\hline & Min & 0.88 & -0.23 & 1.31 & 0.79 & 0.47 & 0.31 & \\
\hline & Mean & 1.96 & 0.84 & 2.27 & 1.82 & 1.51 & 1.24 & \\
\hline & St.dev & 0.37 & 0.32 & 0.35 & 0.38 & 0.40 & 0.38 & \\
\hline \multirow{4}{*}{ VII } & $\operatorname{Max}$ & 3.00 & 1.62 & 3.18 & 2.53 & 2.15 & 1.95 & \multirow{4}{*}{40} \\
\hline & Min & 1.60 & 0.53 & 2.01 & 1.36 & 0.97 & 0.80 & \\
\hline & Mean & 2.35 & 1.11 & 2.66 & 2.00 & 1.62 & 1.40 & \\
\hline & St.dev & 0.28 & 0.27 & 0.31 & 0.29 & 0.29 & 0.28 & \\
\hline \multirow{4}{*}{ VIII } & $\operatorname{Max}$ & 2.80 & 1.80 & 3.37 & 2.97 & 2.34 & 2.01 & \multirow{4}{*}{10} \\
\hline & Min & 2.39 & 1.14 & 2.58 & 2.01 & 1.42 & 1.42 & \\
\hline & Mean & 2.61 & 1.46 & 2.97 & 2.53 & 2.03 & 1.81 & \\
\hline & St.dev & 0.14 & 0.20 & 0.23 & 0.32 & 0.32 & 0.26 & \\
\hline \multirow{4}{*}{ IX } & Max & 2.98 & 1.96 & 3.37 & 3.05 & 2.64 & 2.49 & \multirow{4}{*}{5} \\
\hline & Min & 2.47 & 1.34 & 2.86 & 2.24 & 1.87 & 1.70 & \\
\hline & Mean & 2.77 & 1.74 & 3.11 & 2.73 & 2.28 & 2.05 & \\
\hline & St.dev & 0.26 & 0.28 & 0.23 & 0.34 & 0.29 & 0.32 & \\
\hline $\mathrm{X}$ & $\begin{array}{l}\text { Max } \\
\text { Min } \\
\text { Mean } \\
\text { St.dev }\end{array}$ & 2.91 & 1.95 & 2.97 & 2.72 & 2.49 & 2.42 & 1 \\
\hline
\end{tabular}

we delete the data of MMI X from our dataset. As such, our conversion equations are only applicable within the intensity range of $\mathrm{V} \leq \mathrm{MMI} \leq \mathrm{IX}$.

3.2. Regression Results. In this present study, the orthogonal regression, which is also known as total least square regression or Deming regression [25], has been used to fit our MMI-logPGM data pairs and develop the GMICEs for China. The orthogonal regression calculates the residuals as the minimum perpendicular distance from a point to the regression line. It considers the error on both the dependent and independent variables and has an important advantage for making the equations reversible. This is very useful for GMICEs because we can use the reverse equations to analyze the historical earthquakes which have only seismic intensity information but no ground motion measure data. In addition, according to the statistical results described in the previous section that the low intensity units have a large number of samples while the high intensity units have a small number of samples, we use the mean value of the sample data in each intensity unit to develop the regression to assure the equal weight for all intensity units.

The GMICEs to estimate MMI from PGM are provided in the following equation:

$$
\mathrm{MMI}=c_{1} \cdot \log \mathrm{PGM}+c_{2},
$$

in which PGM corresponds to PGA, PGV, PSA (0.3 s), PSA $(1.0 \mathrm{~s})$, PSA $(2.0 \mathrm{~s})$, and PSA $(0.3 \mathrm{~s})$ and $c_{1}$ and $c_{2}$ are the fitting coefficients, where $c_{1}$ is the slope obtained from the linear regression and $c_{2}$ is the intercept.
Given the reversibility of the equation, the equation for calculating PGM from MMI is

$$
\log \mathrm{PGM}=\frac{\left(\mathrm{MMI}-c_{2}\right)}{c_{1}} .
$$

Table 3 provides a summary of the coefficients in equations (1) and (2), as well as the corresponding standard deviations of the residuals obtained by applying these equations to the complete dataset, for both logPGM and MMI. Regression lines for PGA and PGV are shown in Figure 10 (regression lines for PSA are shown in Figure 11).

In Figure 10(a), we take the MMI-PGA relationship derived by Liu et al. [21] as a reference. It is clearly observed that there are significant differences between the two relationships. Under the same value of PGA, the MMI calculated by the equation of Liu et al. [21] is greater than that obtained by the formula developed in this study. The possible reason is because nowadays the buildings in China are more earthquake resistant than those in 1980. Similar trends can be found in the comparison of MMI-PGV relationships shown in Figure 10(b), which is less obvious than that in Figure 10(a).

\section{Residual Analysis for Magnitude, Distance, and Depth Dependence}

We perform a residual analysis of the dataset to identify possible trends related to earthquake magnitude, hypocentral distance, and hypocentral depth. The objective is to quantify the dependence on these factors and calculate residual corrections. Based on the regression relationships 

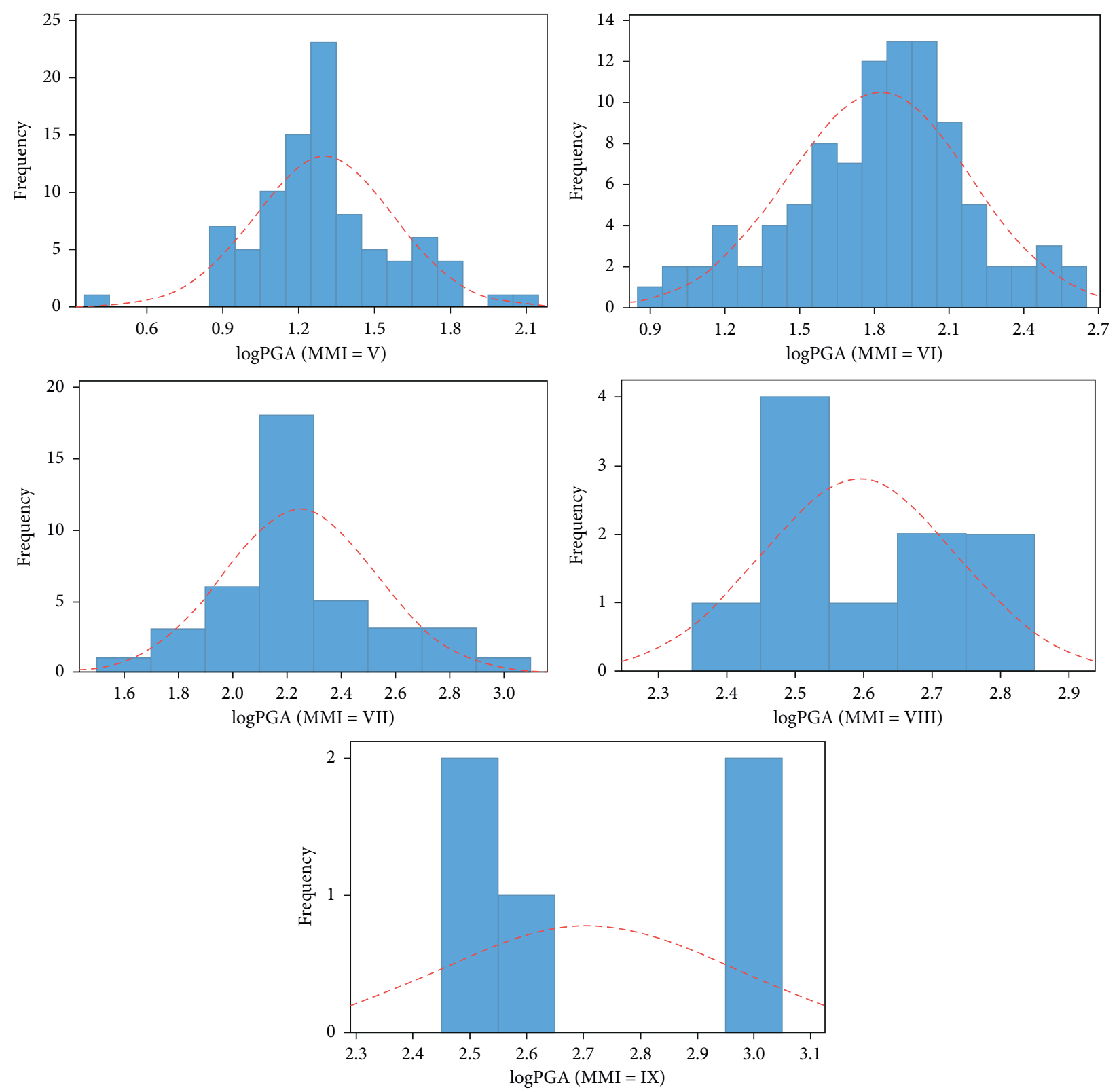

Figure 3: Histograms of the distribution of logPGA.

in equation (1), we calculate the residuals of MMI values (i.e., the difference between the observed MMI and the predicted MMI) and plot the trends of residuals with moment magnitude, hypocentral distance, and hypocentral depth (Figures 12-14, for PGA and PGV; Figures 15-17, for PSA).

To eliminate the dependence of residuals on magnitude, distance, and depth, it is necessary to introduce new variables into the prediction model (equation (1)). Here an approach similar to Worden et al. [6] is adopted. Firstly, we introduce the magnitude correction term:

$$
\gamma_{M}=c_{3} \cdot M+c_{t 1},
$$

where $M$ is the moment magnitude and $c_{3}$ and $c_{t 1}$ are the parameters of the line defining the trend in residuals with magnitude, which are obtained from linear least-squares fit. We then add this correction term to equation (1) and yield an intermediate relationship:

$$
\mathrm{MMI}=c_{1} \cdot \log \mathrm{PGM}+c_{2}+c_{3} \cdot M+c_{t 1} .
$$

Secondly, using the intermediate relationship (equation (4)), we calculate the new residuals of MMI values and introduce the distance correction term:

$$
\gamma_{R}=c_{4} \cdot \log R+c_{t 2},
$$

where $R$ is the hypocentral distance and $c_{4}$ and $c_{t 2}$ are the parameters of the line defining the trend in residuals with distance. Similarly, the distance correction term is added to equation (4) to get an updated intermediate relationship: 

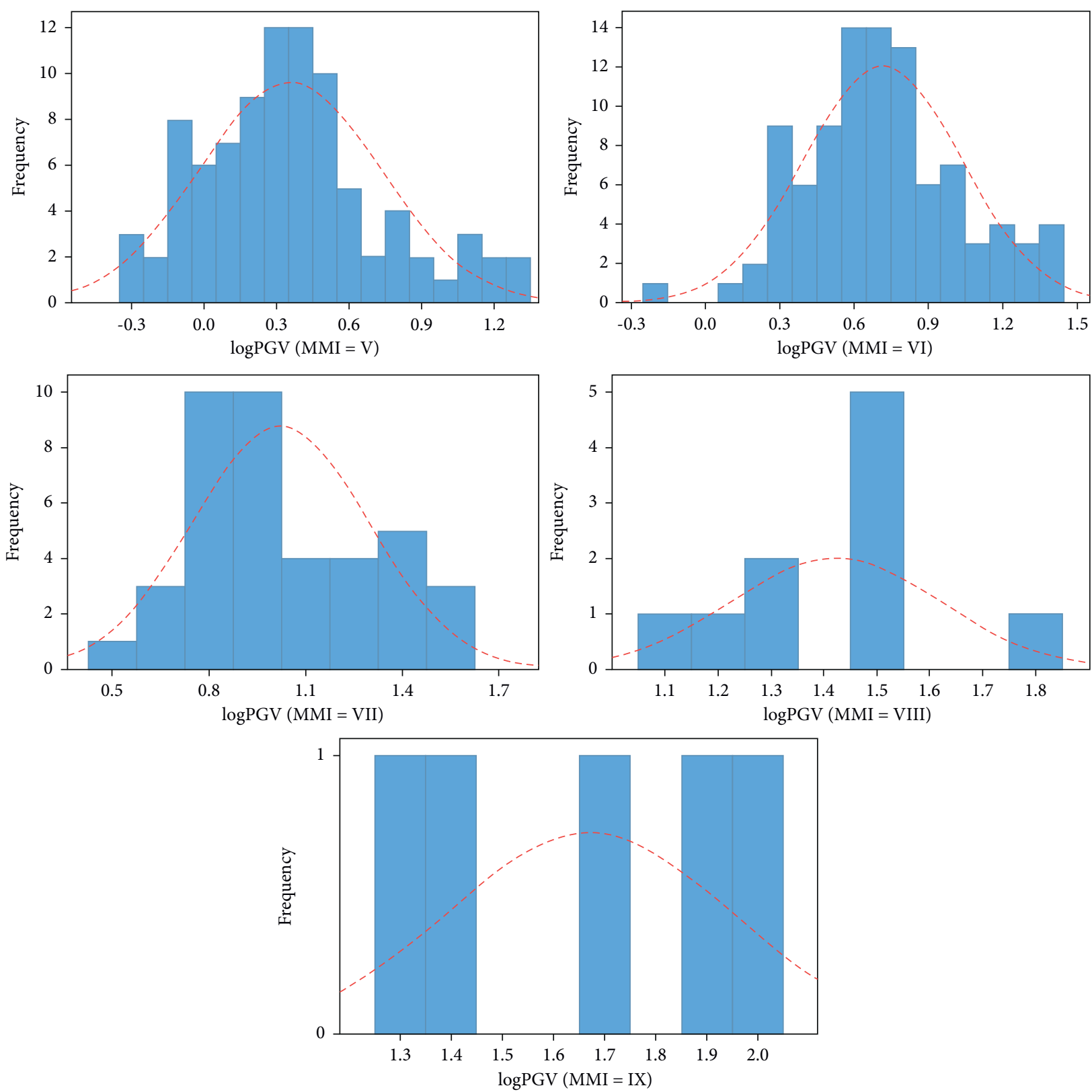

FIGURE 4: Histograms of the distribution of logPGV.

$\mathrm{MMI}=c_{1} \cdot \log \mathrm{PGM}+c_{2}+c_{3} \cdot M+c_{t 1}+c_{4} \cdot \log R+c_{t 2}$.

Lastly, using this new relationship (equation (6)), we calculate the depth correction term:

$$
\gamma_{D}=c_{5} \cdot D+c_{t 3}
$$

where $D$ is the hypocentral depth and $c_{5}$ and $c_{t 3}$ are the parameters of the line defining the trend in residuals with depth. Then, we can obtain the improved prediction relationship:

$$
\mathrm{MMI}=c_{1} \cdot \log \mathrm{PGM}+c_{2}+c_{3} \cdot M+c_{4} \cdot \log R+c_{5} \cdot D+c_{6},
$$

where $c_{6}=c_{t 1}+c_{t 2}+c_{t 3}$.
Table 4 lists the fitted coefficients and the new standard deviations of residuals after applying the correction terms. When we examine the residuals obtained using equation (8) to predict MMI (instead of equation (1)), we note that the trends have been removed. Moreover, as can be seen from a comparison of the sigma values in Table 4 with those in Table 3, the inclusion of magnitude-distance-depth correction terms reduces the standard deviations of the residuals for all ground motion types.

\section{Comparison of the Proposed GMICEs with Previous Studies}

The GMICEs developed in this study (equation (1)) are compared with similar relationships developed for different regions worldwide $[2,4,5,7,8,10-12,17,20-22,26-28]$ to 


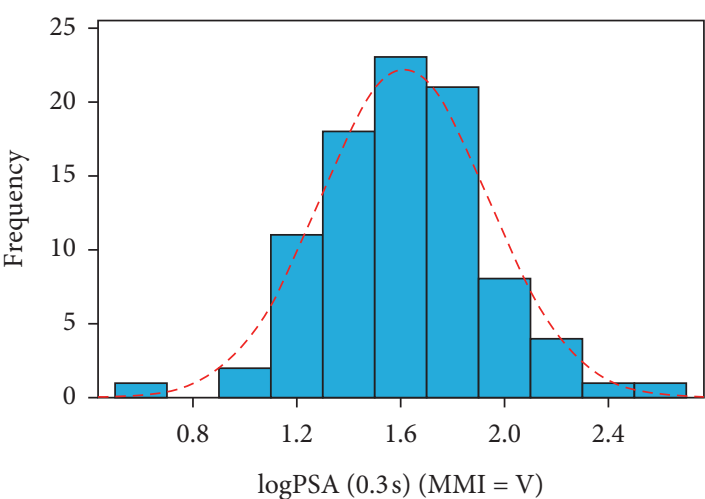

(a)

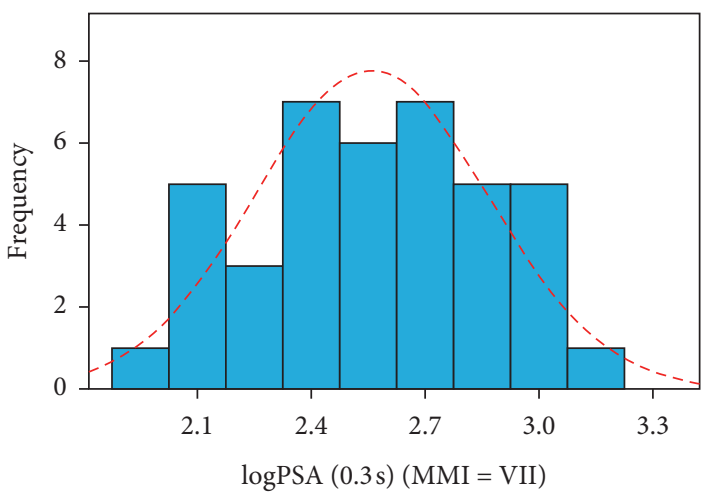

(c)

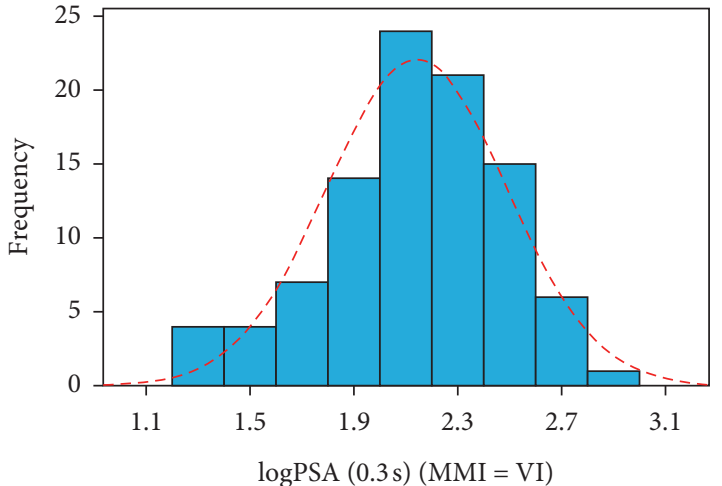

(b)

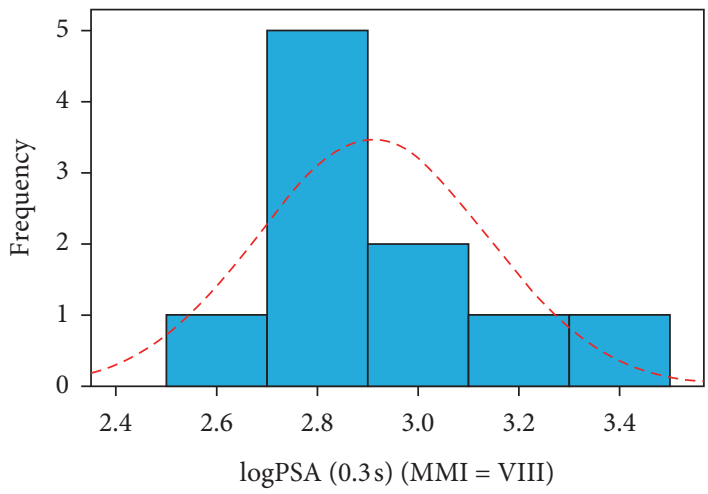

(d)

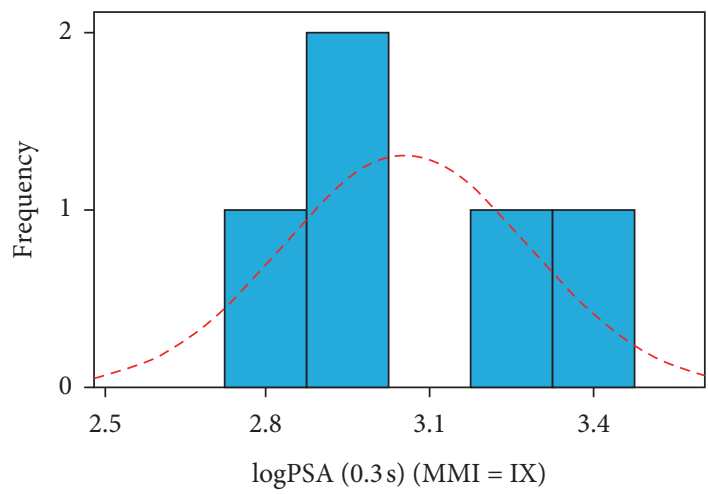

(e)

FIGURE 5: Histograms of the distribution of $\log$ PSA ( $0.3 \mathrm{~s})$.

assess the possible variations from one region to another. The corresponding equations derived by various researchers for comparison are given in Table 5. Figures 18 and 19 present these comparisons in terms of $\log P G A, \log P G V$, and $\log$ PSA, respectively.

As can be seen from Figure 18(a), there are significant discrepancies in the various studies for MMI-PGA relationships. Liu et al. [21], Trifunac and Brady [20], and Faenza and Michelini [2] overestimate intensity values at all intensity levels, whereas Wald et al. [3] and Worden et al. [6] underestimate the intensity values approximately for all intensity levels. Additionally, Atkinson and Kaka [5], Ma et al. [27], Caprio et al. [10], Du et al. [22], Ahmadzadeh et al. [12], and Mortalla et al. [11] present different slopes leading to underestimating the values at low levels and overestimating at higher levels.

By comparing the MMI-PGV relationships in Figure 18(b), it is observed that Liu et al. [21], Atkinson and Kaka [5], Du et al. [22], and Ahmadzadeh et al. [12] are nearly consistent with our proposed relation. Faenza and Michelini [2] overestimate intensity values at all intensity levels, whereas Wald et al. [3], Worden et al. [6], and 


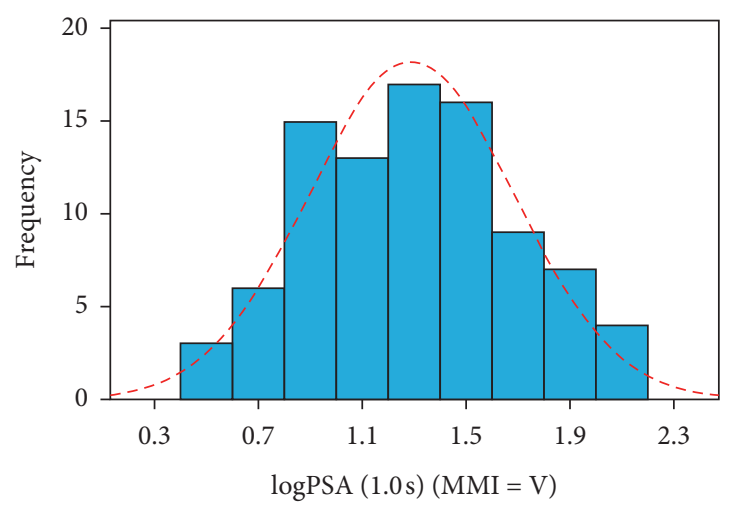

(a)

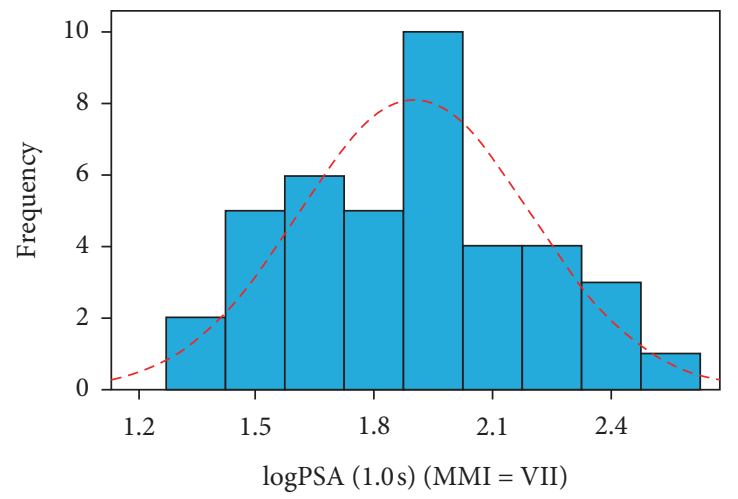

(c)

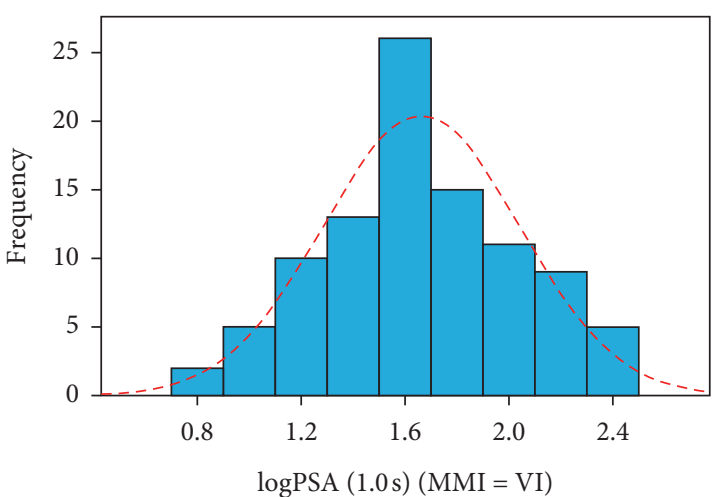

(b)

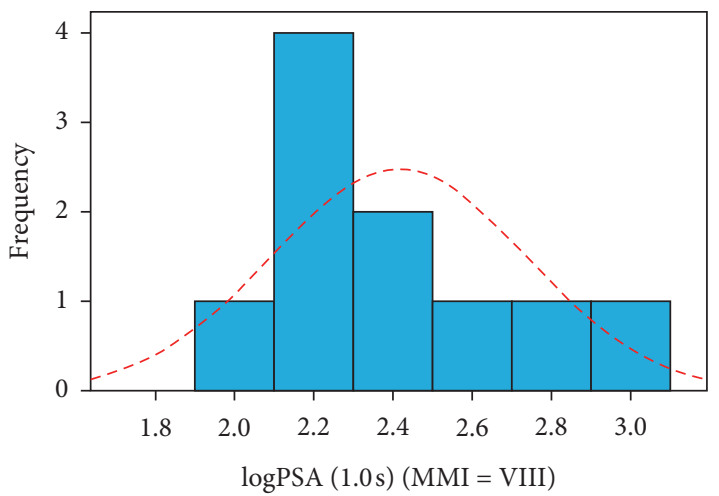

(d)

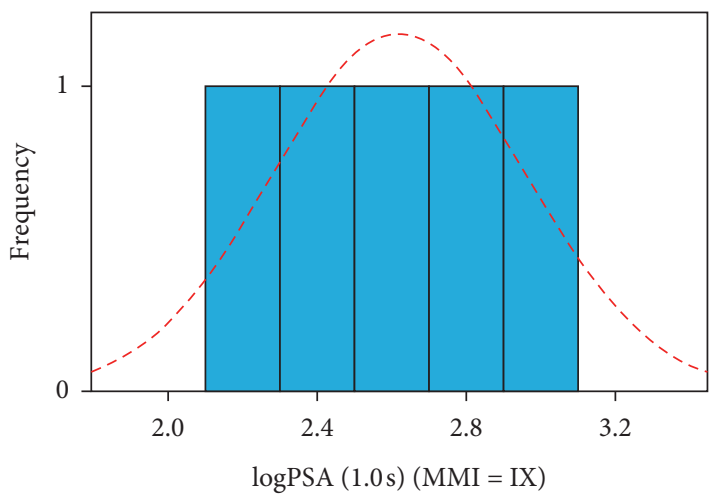

(e)

FIGURE 6: Histograms of the distribution of $\log$ PSA (1.0 s).

Mortalla et al. [11] underestimate the intensity values for all intensity levels. Additionally, Ma et al. [27] and Caprio et al. [10] overestimate the intensity values at low levels but underestimate at higher levels, whereas Trifunac and Brady's study [20] has the opposite trend, leading to underestimating the values at low levels and overestimating at higher levels.

Similar discrepancies can be found from the comparison of MMI-PSA relationships shown in Figure 19. It should be also noted that, when comparing the MMI-PSA curves under different natural vibration periods $(0.3 \mathrm{~s}, 1.0 \mathrm{~s}$, $2.0 \mathrm{~s}$, and $3.0 \mathrm{~s}$ ) for a given intensity unit, the PSA value is larger in the shorter period and smaller in the longer period, which is consistent with the results of Worden et al. [6] and Panjamani et al. [26]. This interesting observation may be related to the types of buildings and structures in the study areas.

Through the above analysis, we can see that the GMICEs obtained by different scholars exhibit a big discrepancy. Because these relations are obtained from the strong motion records and seismic intensity dataset in different regions, the differences between them are believed to originate from the variable ground motion characteristics(frequency components, duration, and so on) as well as different building and damage styles in these regions. As a result, it is important to note that the GMICEs carry regional characteristics and 


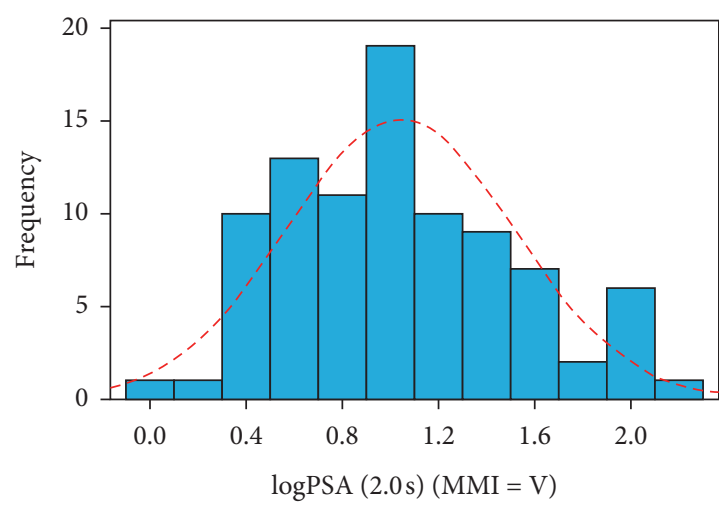

(a)

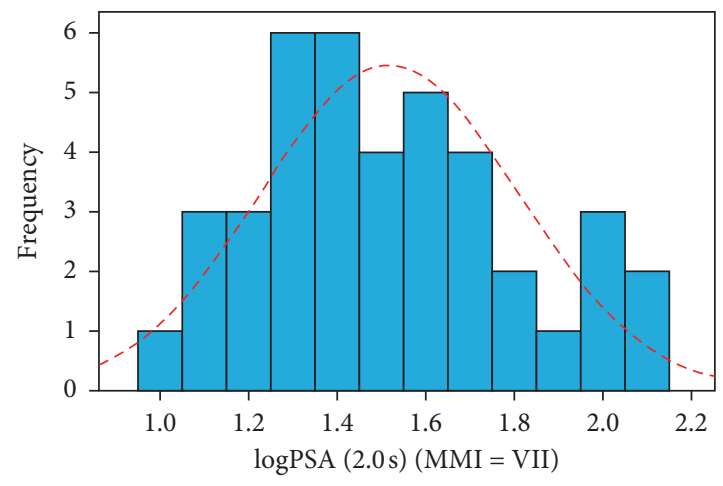

(c)

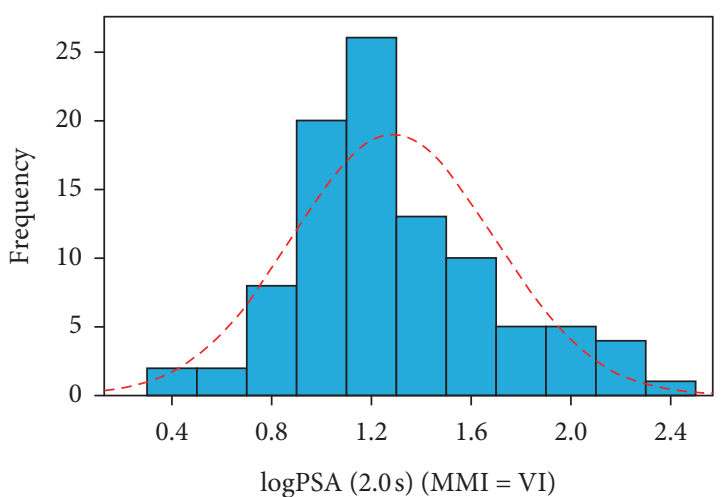

(b)

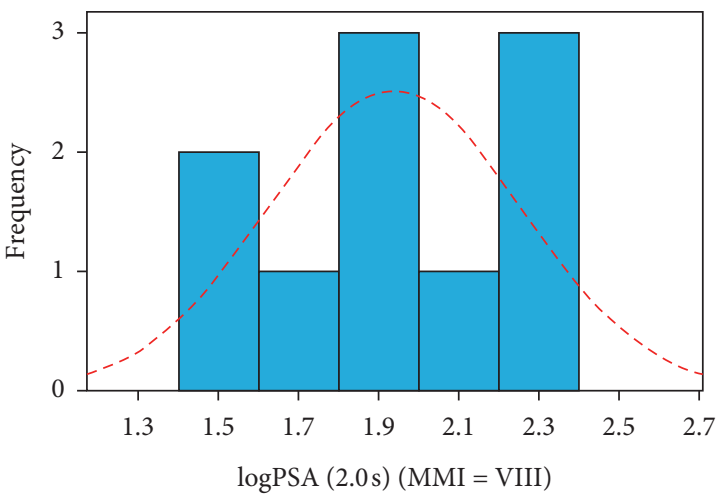

(d)

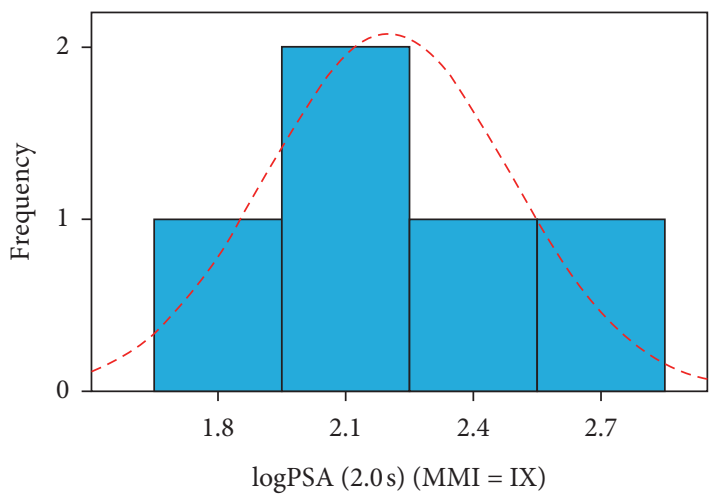

(e)

FIGURE 7: Histograms of the distribution of $\log$ PSA (2.0 s).

should only be applied in regions with similar seismic design and construction practices.

\section{Regional Scaling Factor for Global Relationships}

To quantify the differences to other regions in the globe by having the global relationships as reference, as well as providing an alternative approach to the GMICEs proposed here, a regional correction factor for China to the global relationships proposed by Caprio et al. [10] is applied. Through a residual analysis of the global relationships applied to the China database, the mean and variance are calculated and defined as the regional correction factor. Caprio et al. [10] gave the regional correction factors for Italy, Greece, and California, and our regional correction factor for China can now be added to the global relationships, as shown in the following equation:

$$
\begin{aligned}
& \gamma_{\mathrm{PGA}}=0.23 \pm 0.96, \\
& \gamma_{\mathrm{PGV}}=0.03 \pm 0.81 .
\end{aligned}
$$

These equations indicate that the global relationships underestimate the China dataset by about $0.23 \pm 0.96$ intensity units for PGA and $0.03 \pm 0.81$ for PGV. It should be noted that since there is no global conversion relationship 


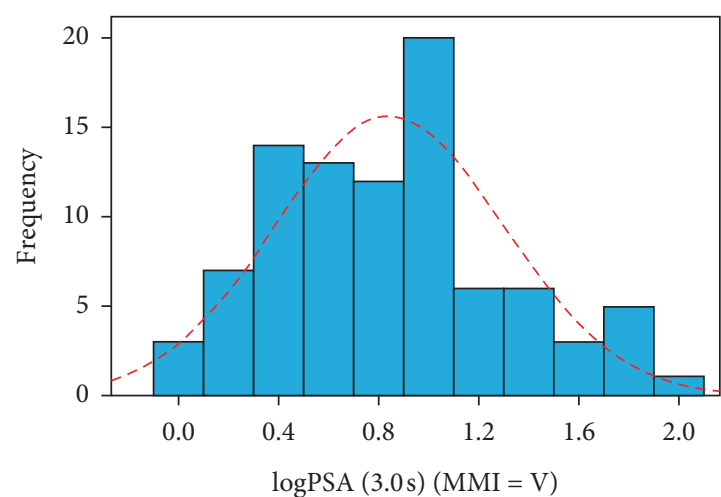

(a)

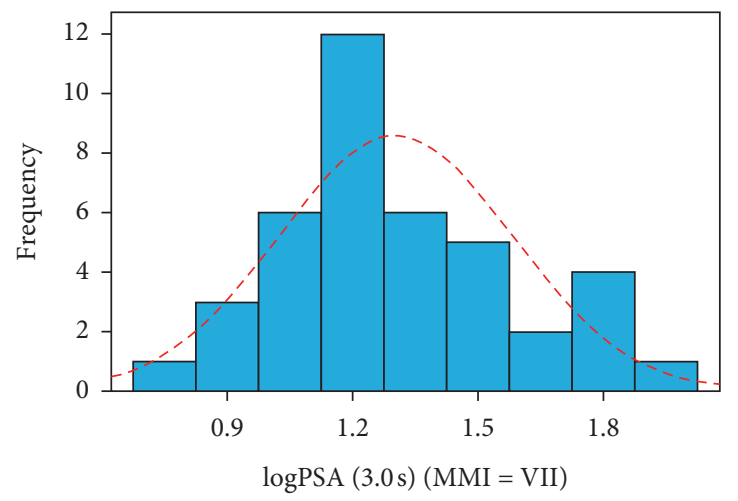

(c)

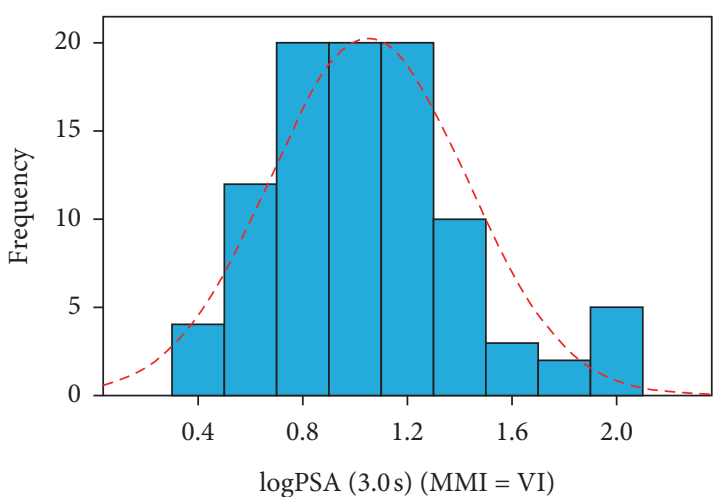

(b)

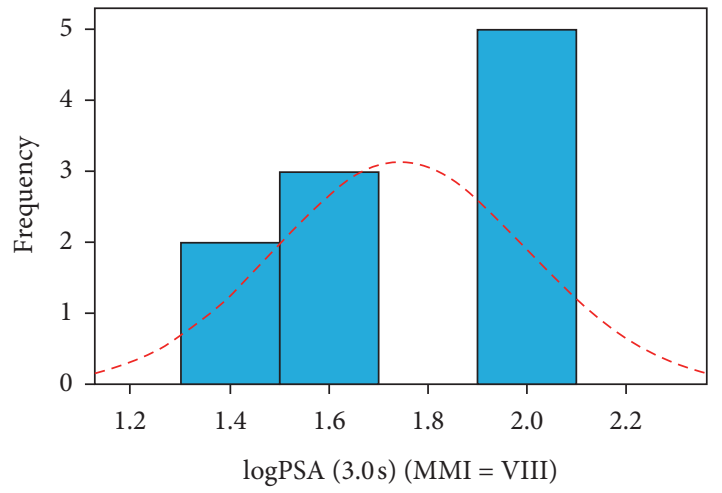

(d)

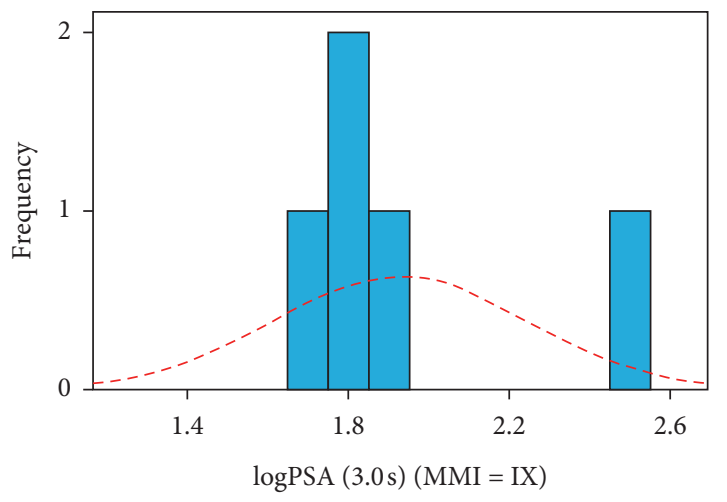

(e)

FIgURE 8: Histograms of the distribution of logPSA (3.0 s). 

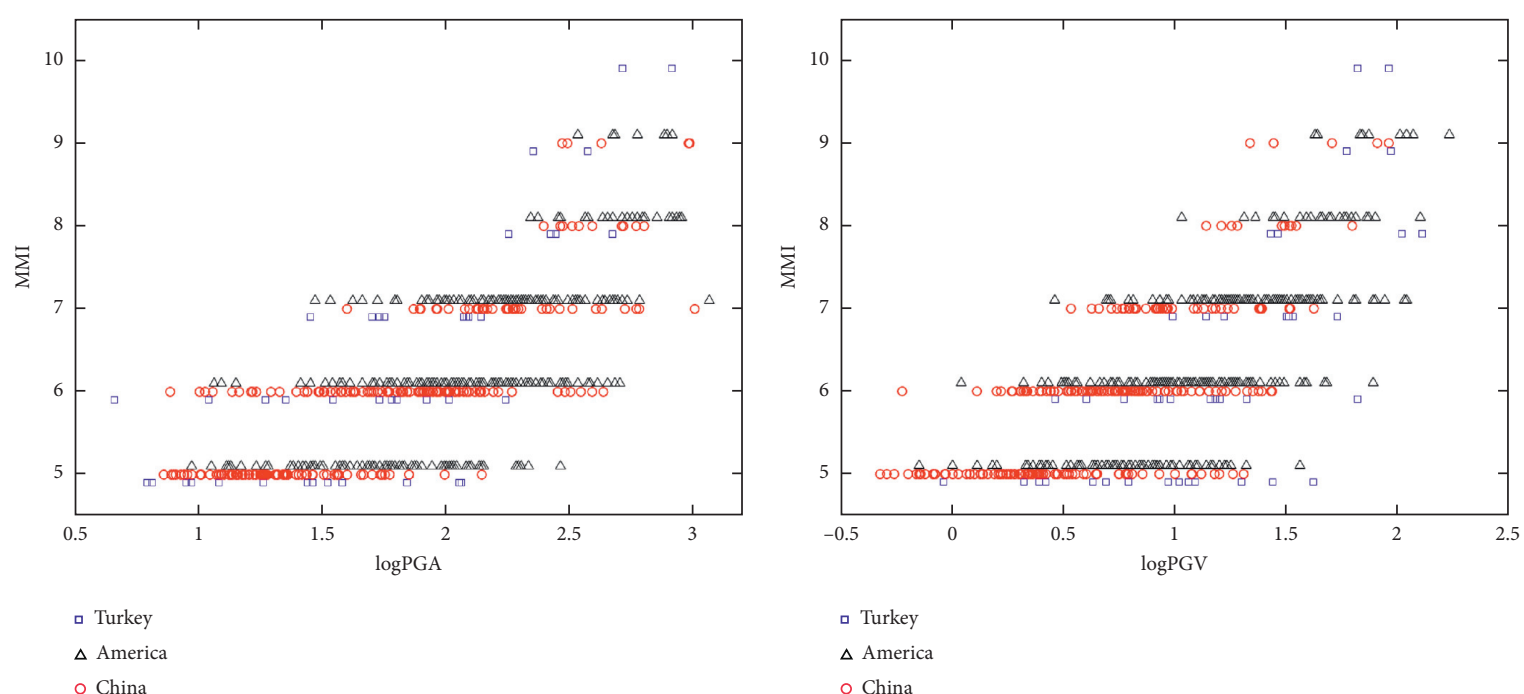

(a)

(b)

Figure 9: Distribution of datasets from China, America, and Turkey. (a) MMI versus logPGA. (b) MMI versus logPGV.

TABLE 3: Coefficients of equation (1) and standard deviations of residuals for the complete dataset.

\begin{tabular}{lcccc}
\hline PGM & $c_{1}$ & $c_{2}$ & $\sigma_{\text {MMI }}$ & 0.6069 \\
PGA & 2.906 & 0.554 & 0.6742 & 0.3257 \\
PGV & 3.310 & 3.233 & 0.6140 & 0.3280 \\
PSA (0.3 s) & 2.873 & -0.327 & 0.7027 & 0.3390 \\
PSA (1.0 s) & 3.065 & 0.540 & 1.0265 & 0.3675 \\
PSA (2.0 s) & 4.082 & -0.152 & 1.0118 & 0.4115 \\
PSA (3.0 s) & 4.062 & 0.817 & & 0.3912 \\
\hline
\end{tabular}

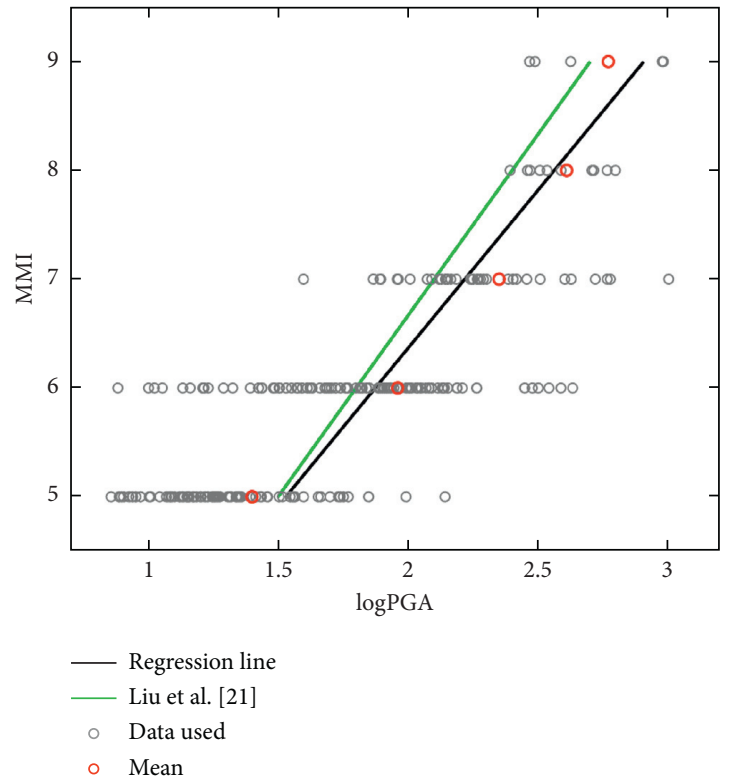

(a)

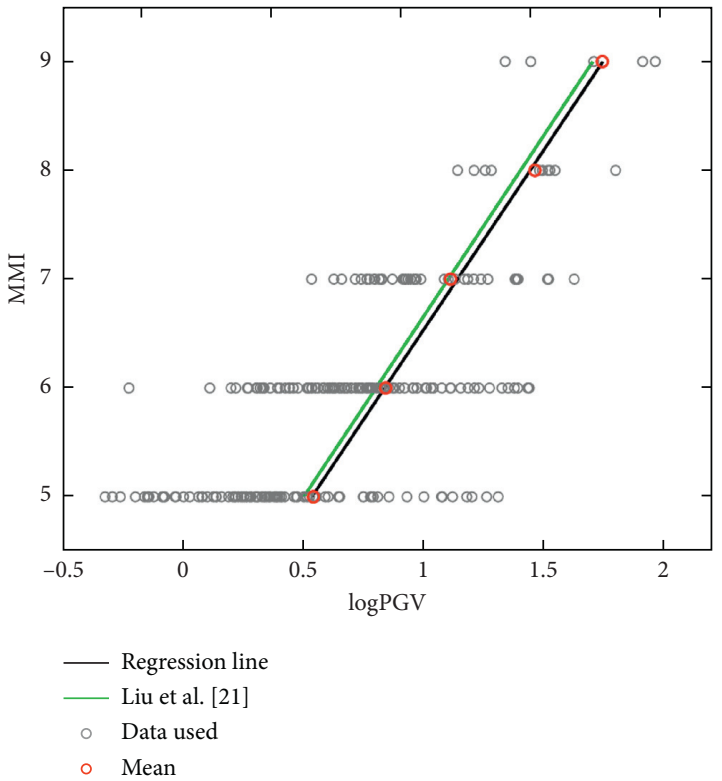

(b)

Figure 10: Regression lines of GMICEs. (a) MMI-logPGA. (b) MMI-logPGV. 

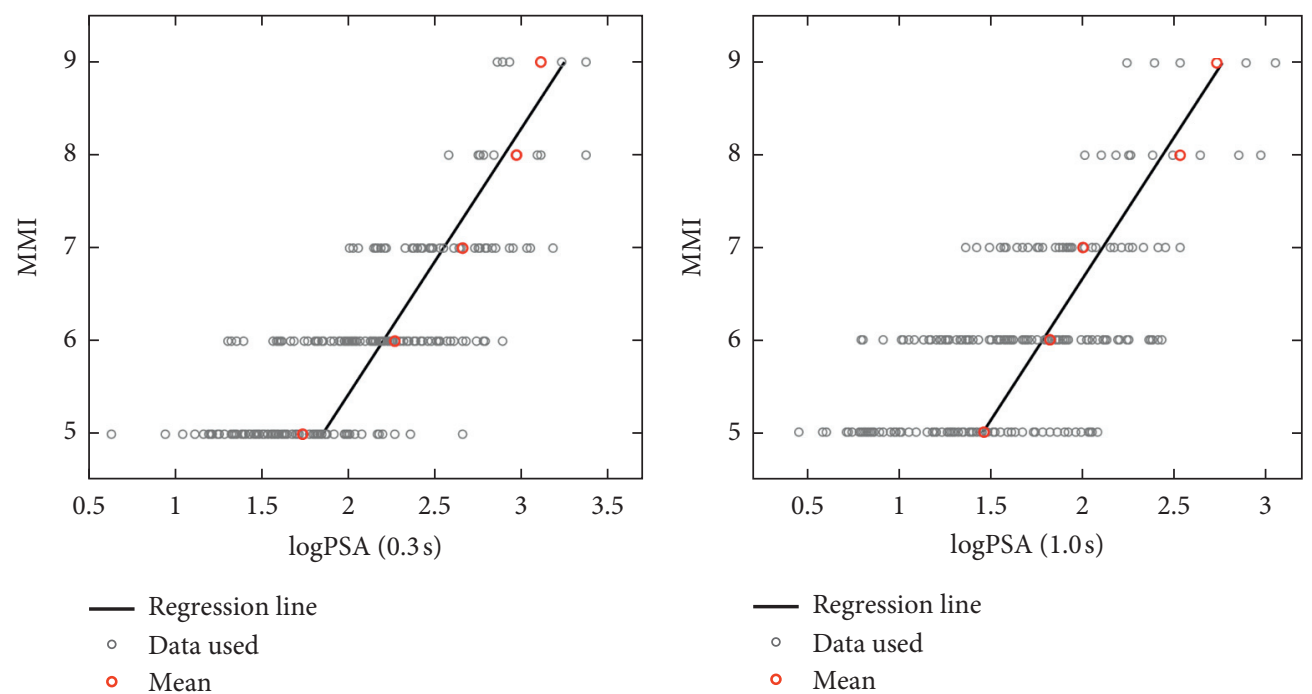

(a)

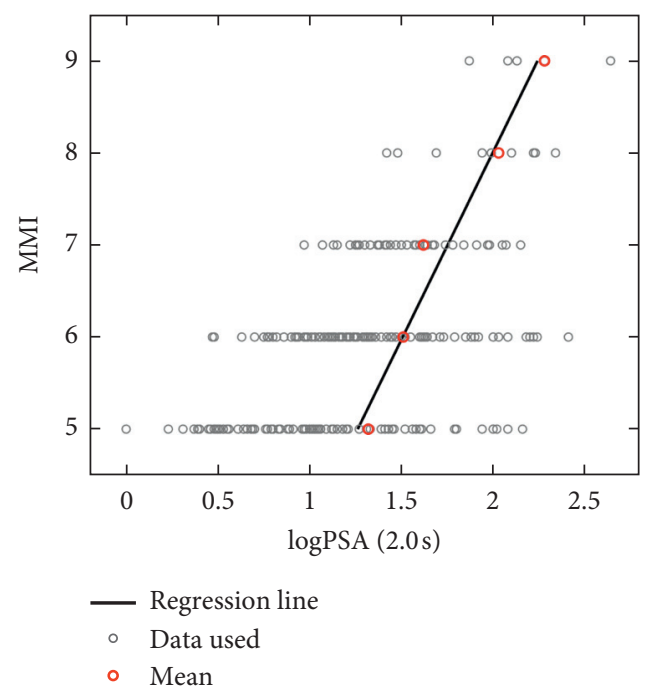

(c)

- Regression line

- Data used

- Mean

(b)

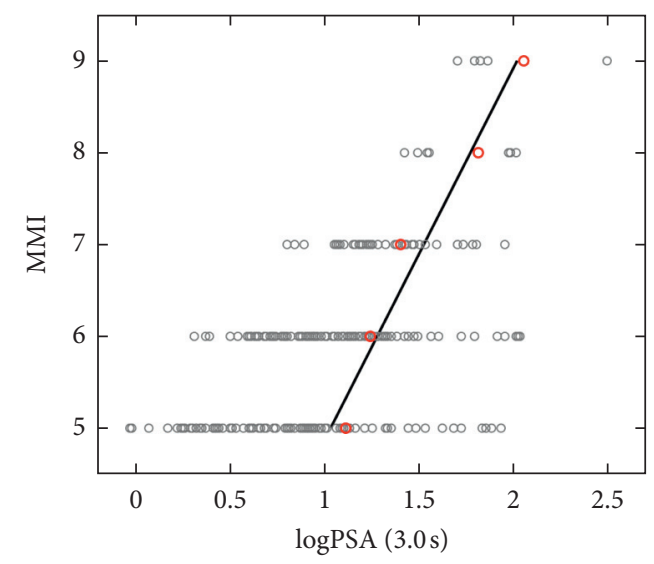

— Regression line

- Data used

- Mean

Figure 11: Regression lines of GMICEs. (a) MMI-logPSA (0.3 s). (b) MMI-logPSA (1.0 s). (c) MMI-logPSA (2.0 s). (d) MMI-logPSA (3.0 s).

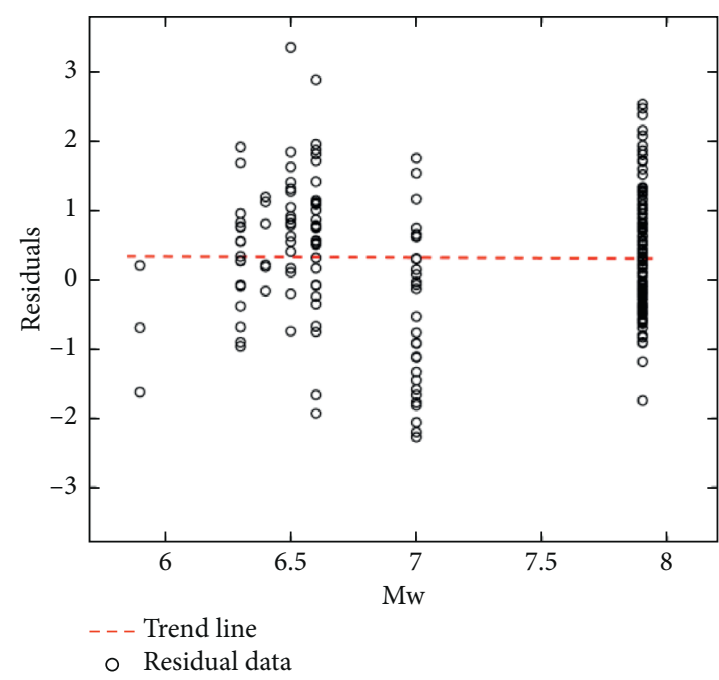

(a)

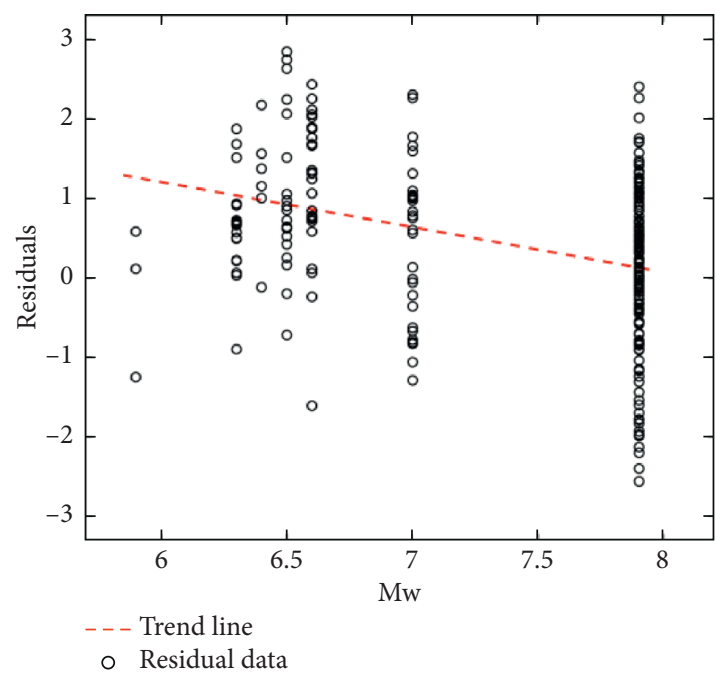

(b)

FIGURE 12: Residuals for MMI predicted from (a) PGA and (b) PGV, as a function of moment magnitude. 


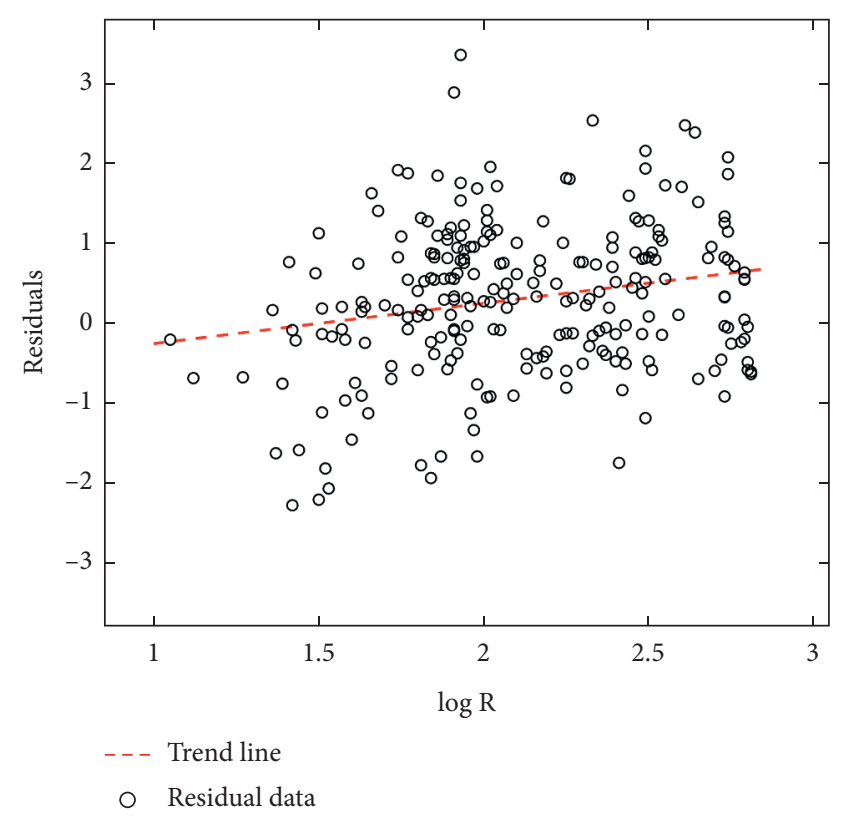

(a)

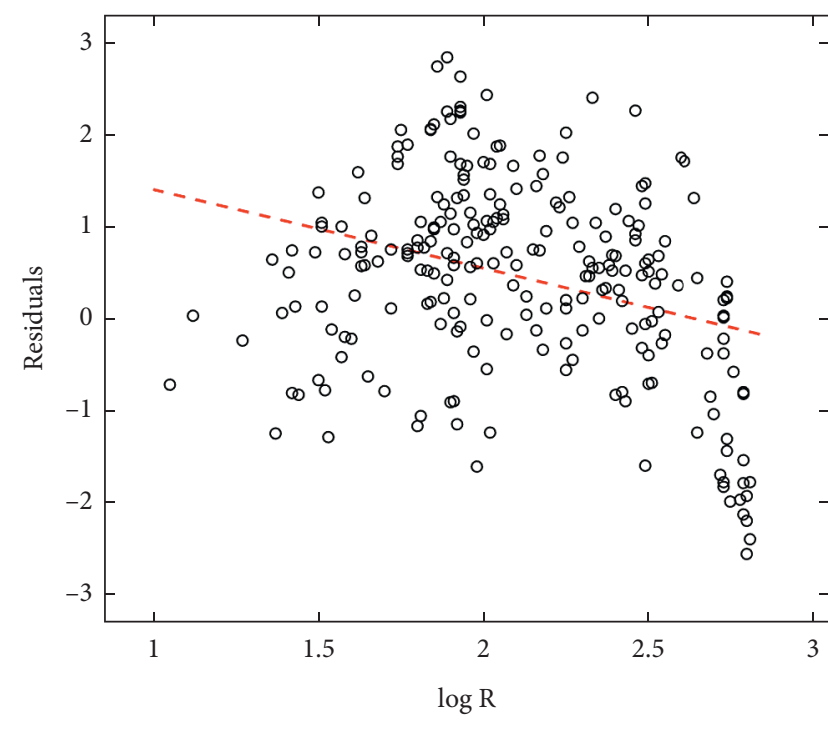

- - - Trend line

- Residual data

(b)

Figure 13: Residuals for MMI predicted from (a) PGA and (b) PGV, as a function of the log of hypocentral distance.

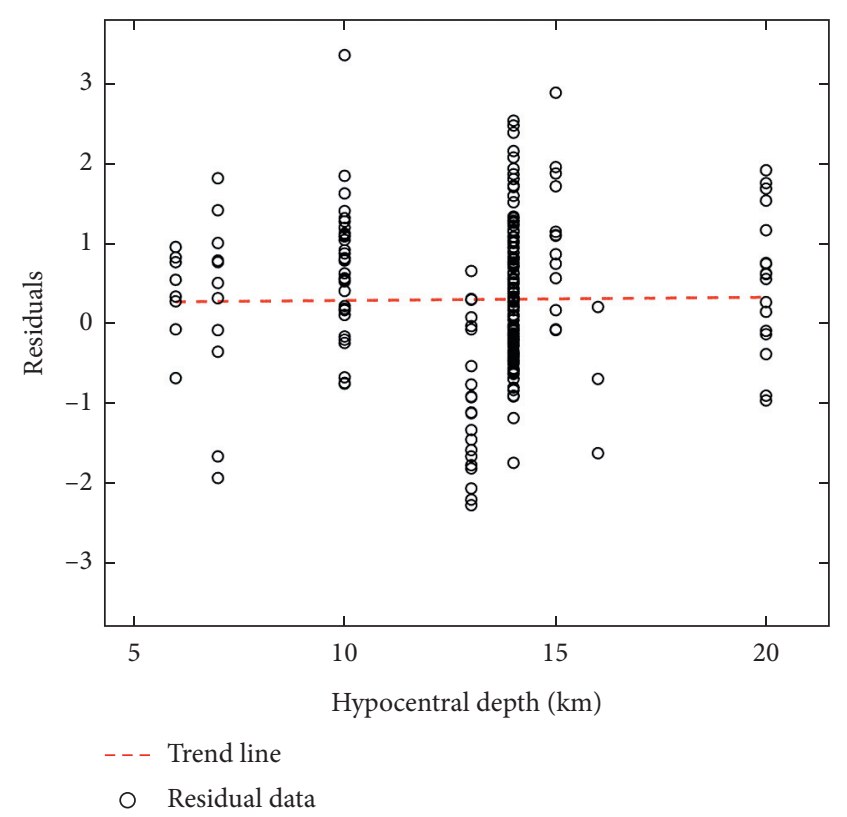

(a)

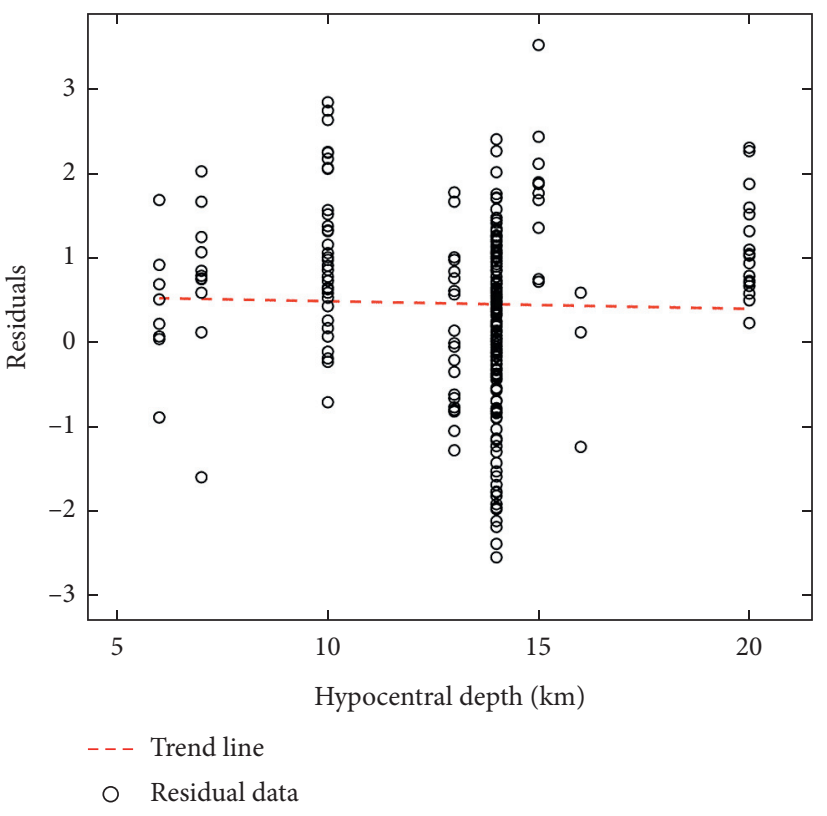

(b)

FIgure 14: Residuals for MMI predicted from (a) PGA and (b) PGV, as a function of hypocentral depth. 


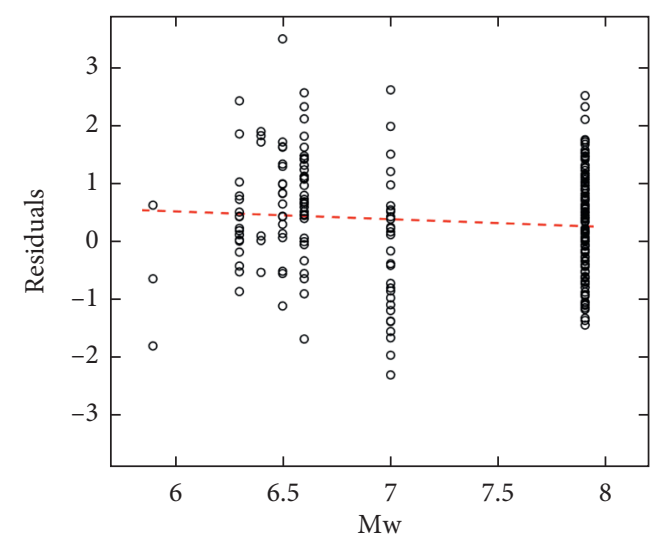

- - - Trend line

- Residual data

(a)

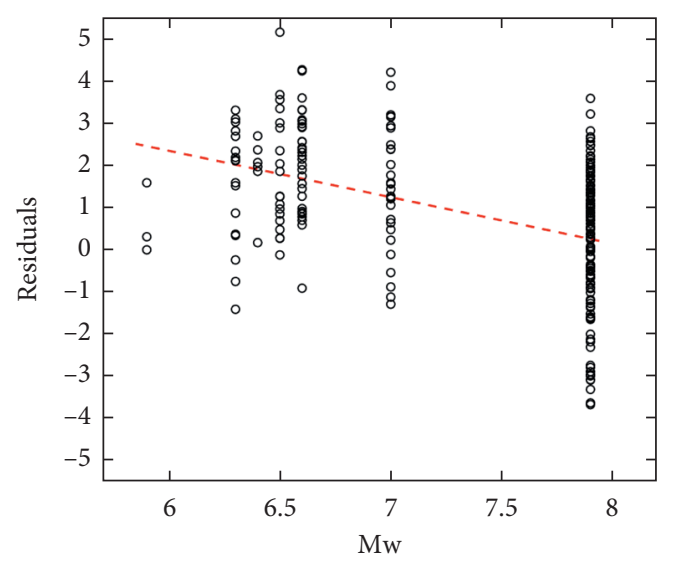

- - Trend line

- Residual data

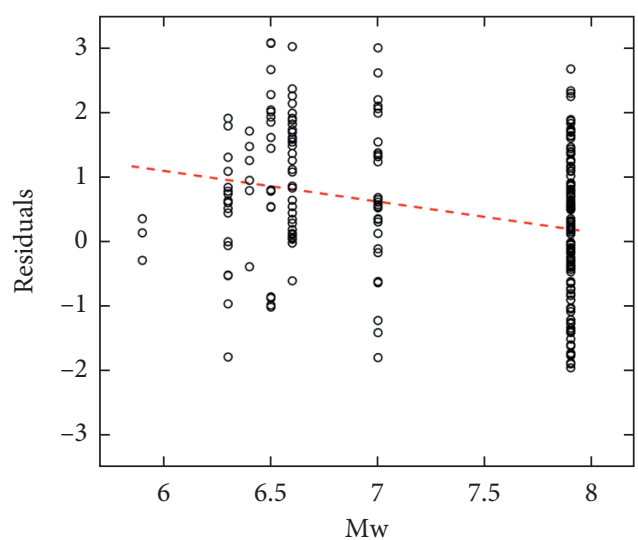

- - - Trend line

- Residual data

(b)

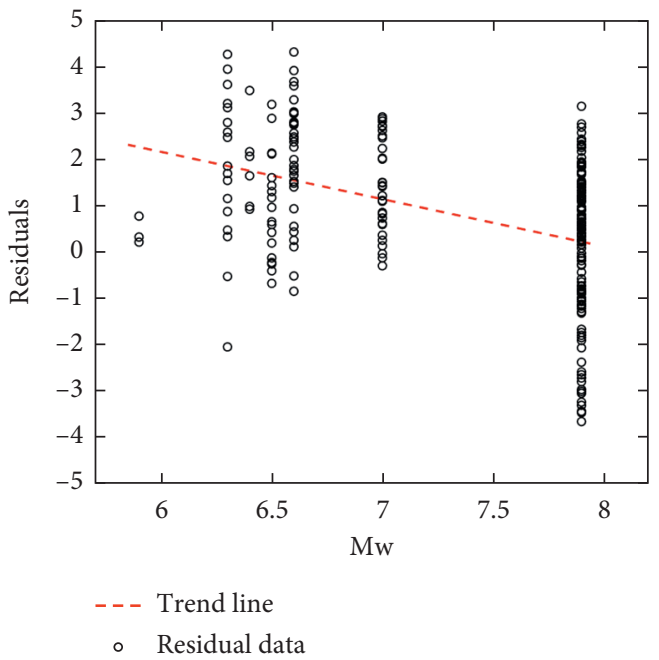

(d)

Figure 15: Residuals for MMI predicted from (a) PSA (0.3 s), (b) PSA (1.0 s), (c) PSA (2.0 s), and (d) PSA (3.0 s), as a function of moment magnitude.

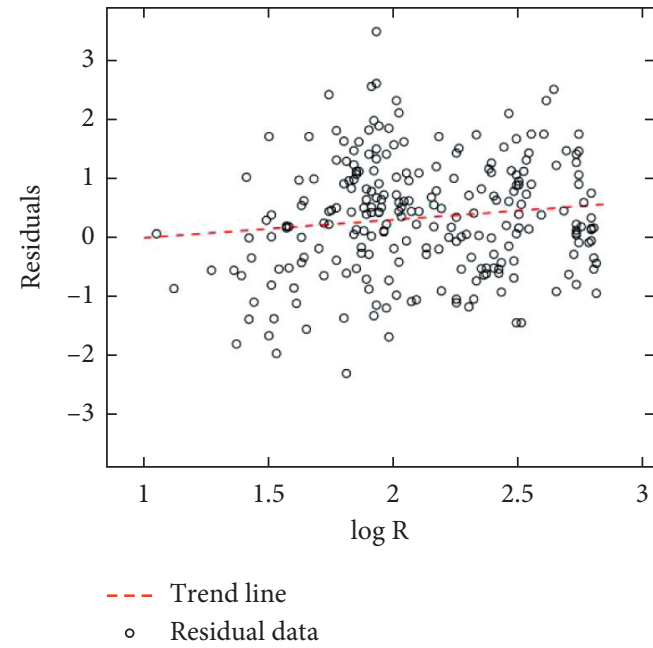

(a)

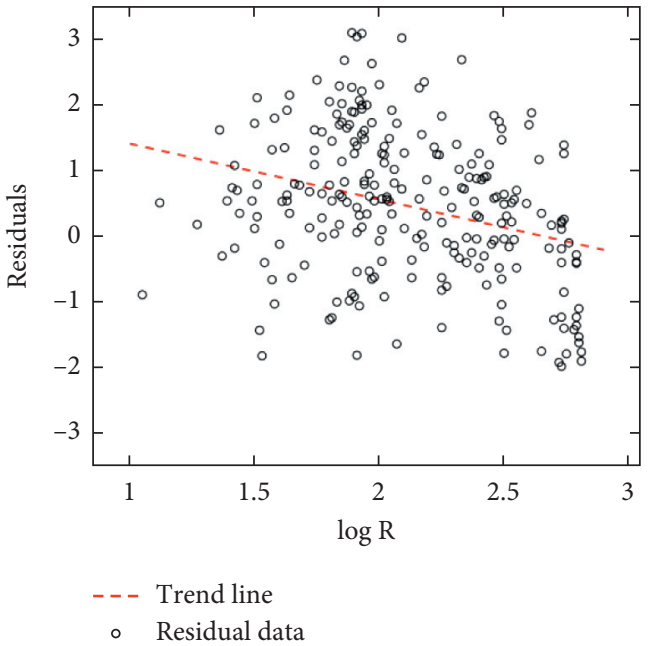

(b)

Figure 16: Continued. 


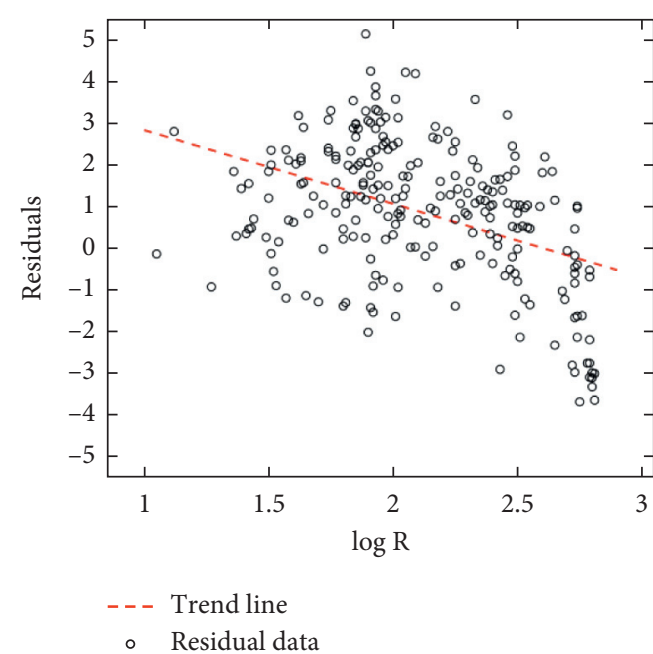

(c)

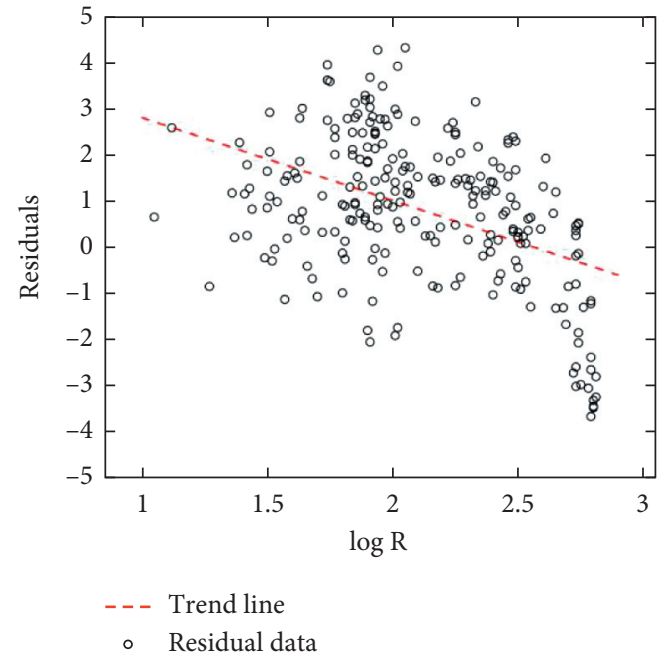

(d)

Figure 16: Residuals for MMI predicted from (a) PSA (0.3 s), (b) PSA (1.0 s), (c) PSA (2.0 s), and (d) PSA (3.0 s), as a function of the log of hypocentral distance.

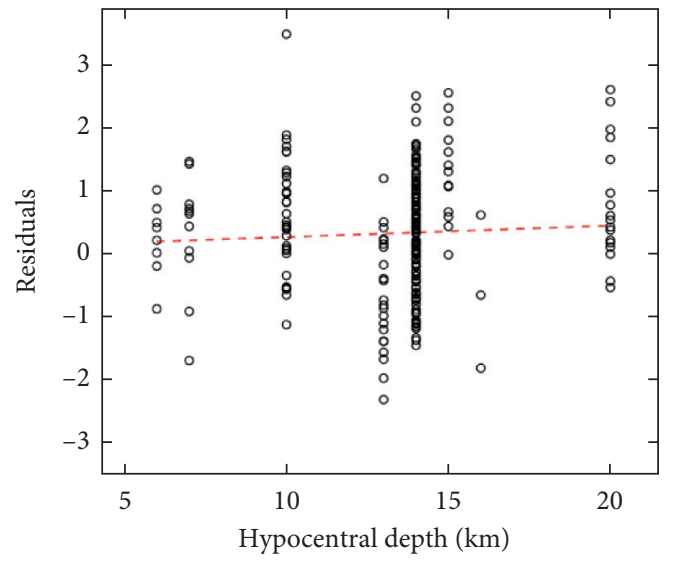

- - - Trend line

- Residual data

(a)

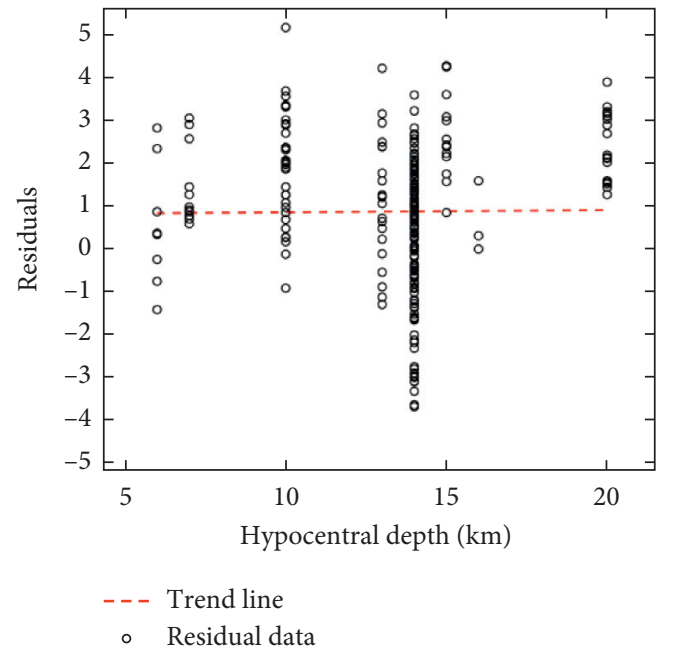

(c)

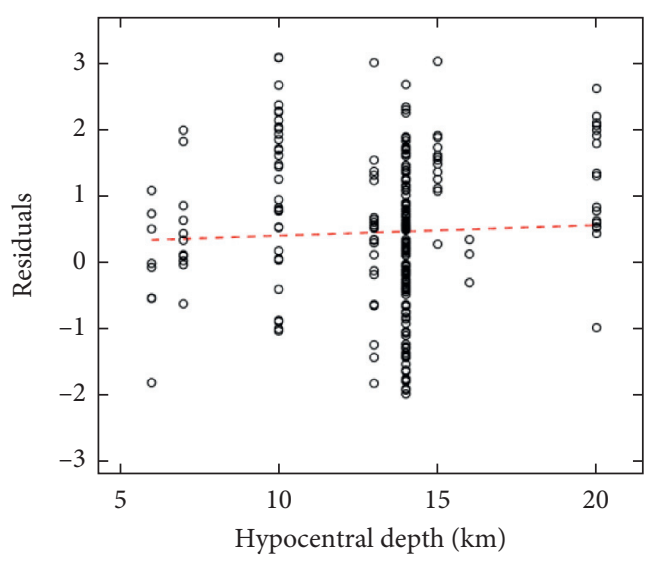

_. - Trend line

- Residual data

(b)

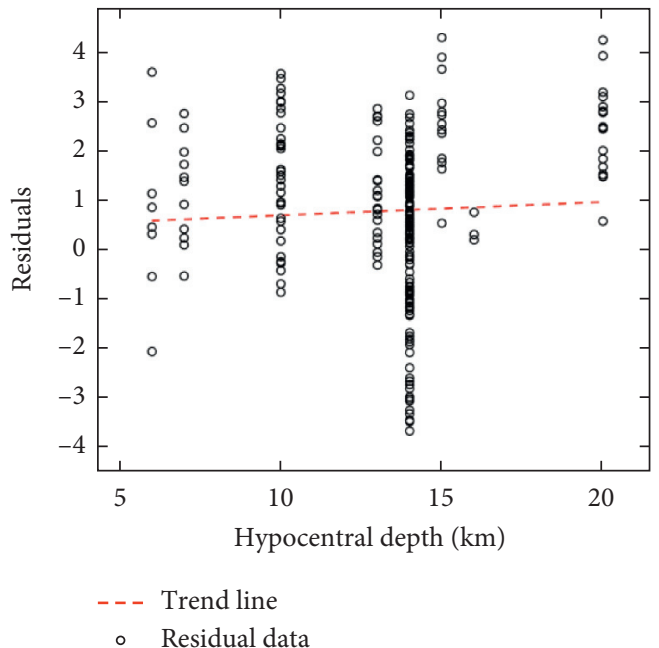

(d)

FIGURE 17: Residuals for MMI predicted from (a) PSA (0.3 s), (b) PSA (1.0 s), (c) PSA (2.0 s), and (d) PSA (3.0 s), as a function of hypocentral depth. 
TABLE 4: Coefficients of equation (8) and standard deviations of residuals applying the correction terms.

\begin{tabular}{lcccrr}
\hline PGM & $c_{3}$ & $c_{4}$ & $c_{5}$ & $c_{6}$ & -0.595 \\
PGA & -0.016 & 0.523 & -0.006 & 4.529 & 0.5698 \\
PGV & -0.567 & -0.189 & 0.035 & 0.116 & 0.6068 \\
PSA (0.3 s) & -0.135 & 0.467 & 0.016 & 3.818 & 0.5566 \\
PSA (1.0 s) & -0.480 & -0.287 & 0.057 & 8.665 & 0.6240 \\
PSA (2.0 s) & -1.101 & -0.473 & 0.095 & 0.8555 \\
PSA (3.0 s) & -1.020 & -0.594 & 0.114 & 8.016 & 0.8062 \\
\hline
\end{tabular}

TABLE 5: GMICEs from the present and previous studies.

\begin{tabular}{|c|c|c|}
\hline & Reference study & Proposed equations \\
\hline \multirow{8}{*}{ MMI-PGA } & $\begin{array}{l}\text { This study } \\
\text { Liu et al. [21] } \\
\text { Ma et al. [27] } \\
\text { Du et al. [22] }\end{array}$ & $\begin{array}{c}I=2.906 \cdot \log \mathrm{PGA}+0.554 \\
I=3.333 \cdot \log \mathrm{PGA} \\
I=2.15 \cdot \log \mathrm{PGA}+2.12 \\
I=3.311 \cdot \log \mathrm{PGA}-0.354\end{array}$ \\
\hline & Trifunac and Brady [20] & $I=3.333 \cdot \log \mathrm{PGA}-0.047$ \\
\hline & Wald et al. [3] & $\begin{array}{l}I=2.20 \cdot \log \mathrm{PGA}+1.00, \log \mathrm{PGA} \leq 1.82 \\
I=3.66 \cdot \log \mathrm{PGA}-1.66, \log \mathrm{PGA}>1.82\end{array}$ \\
\hline & $\begin{array}{l}\text { Atkinson and Kaka [5] } \\
\text { Faenza and Michelini [2] }\end{array}$ & $\begin{array}{c}I=1.39 \cdot \log \mathrm{PGA}+2.65, \log \mathrm{PGA} \leq 1.69 \\
I=4.09 \cdot \log \mathrm{PGA}-1.91, \log \mathrm{PGA}>1.69 \\
I=2.58 \cdot \log \mathrm{PGA}+1.68\end{array}$ \\
\hline & Worden et al. [6] & $\begin{array}{l}I=1.55 \cdot \log \mathrm{PGA}+1.78, \log \mathrm{PGA} \leq 1.57 \\
I=3.70 \cdot \log \mathrm{PGA}-1.60, \log \mathrm{PGA}>1.57\end{array}$ \\
\hline & Caprio et al. [10] & $\begin{array}{l}I=1.647 \cdot \log \mathrm{PGA}+2.270, \log \mathrm{PGA} \leq 1.6 \\
I=3.822 \cdot \log \mathrm{PGA}-1.361, \log \mathrm{PGA}>1.6\end{array}$ \\
\hline & Ahmadzadeh et al. [12] & $I=3.47 \cdot \log \mathrm{PGA}-0.58$ \\
\hline & Mortalla et al. [11] & $\begin{array}{l}I=1.9920 \cdot \log \mathrm{PGA}+1.7601, \log \mathrm{PGA}<1.8914 \\
I=3.9322 \cdot \log \mathrm{PGA}-1.9095, \log \mathrm{PGA} \geq 1.8914\end{array}$ \\
\hline \multirow{9}{*}{ MMI-PGV } & $\begin{array}{l}\text { This study } \\
\text { Liu et al. [21] } \\
\text { Ma et al. [27] } \\
\text { Du et al. [22] }\end{array}$ & $\begin{array}{c}I=3.310 \cdot \log P G V+3.233 \\
I=3.333 \cdot \log P G V+3.333 \\
I=2.31 \cdot \log P G V+4.68 \\
I=3.356 \cdot \log P G V+3.315\end{array}$ \\
\hline & Trifunac and Brady [20] & $I=4.000 \cdot \log \mathrm{PGV}+2.520$ \\
\hline & Wald et al. [3] & $\begin{array}{l}I=2.10 \cdot \log \mathrm{PGV}+3.40, \log \mathrm{PGV} \leq 0.76 \\
I=3.47 \cdot \log \mathrm{PGV}+2.35, \log \mathrm{PGV}>0.76\end{array}$ \\
\hline & Atkinson and Kaka [5] & $\begin{array}{l}I=1.32 \cdot \log \mathrm{PGV}+4.37, \log \mathrm{PGA} \leq 0.48 \\
I=3.03 \cdot \log \mathrm{PGV}+3.54, \log \mathrm{PGV}>0.48\end{array}$ \\
\hline & Faenza and Michelini [2] & $I=2.35 \cdot \log \mathrm{PGV}+5.11$ \\
\hline & Worden et al. [6] & $\begin{array}{l}I=1.47 \cdot \log P G V+3.78, \log P G V \leq 0.53 \\
I=3.16 \cdot \log P G V+2.89, \log P G V>0.53\end{array}$ \\
\hline & Caprio et al. [10] & $\begin{array}{l}I=1.589 \cdot \log \mathrm{PGV}+4.424, \log \mathrm{PGV} \leq 0.3 \\
I=2.671 \cdot \log \mathrm{PGV}+4.018, \log \mathrm{PGV}>0.3\end{array}$ \\
\hline & Ahmadzadeh et al. [12] & $I=3.31 \cdot \log \mathrm{PGV}+3.35$ \\
\hline & Mortalla et al. [11] & $\begin{array}{l}I=1.6323 \cdot \log \mathrm{PGV}+4.1070, \log \mathrm{PGV}<1.0024 \\
I=3.8370 \cdot \log \mathrm{PGV}+1.8970, \log \mathrm{PGV} \geq 1.0024\end{array}$ \\
\hline
\end{tabular}


TABle 5: Continued.

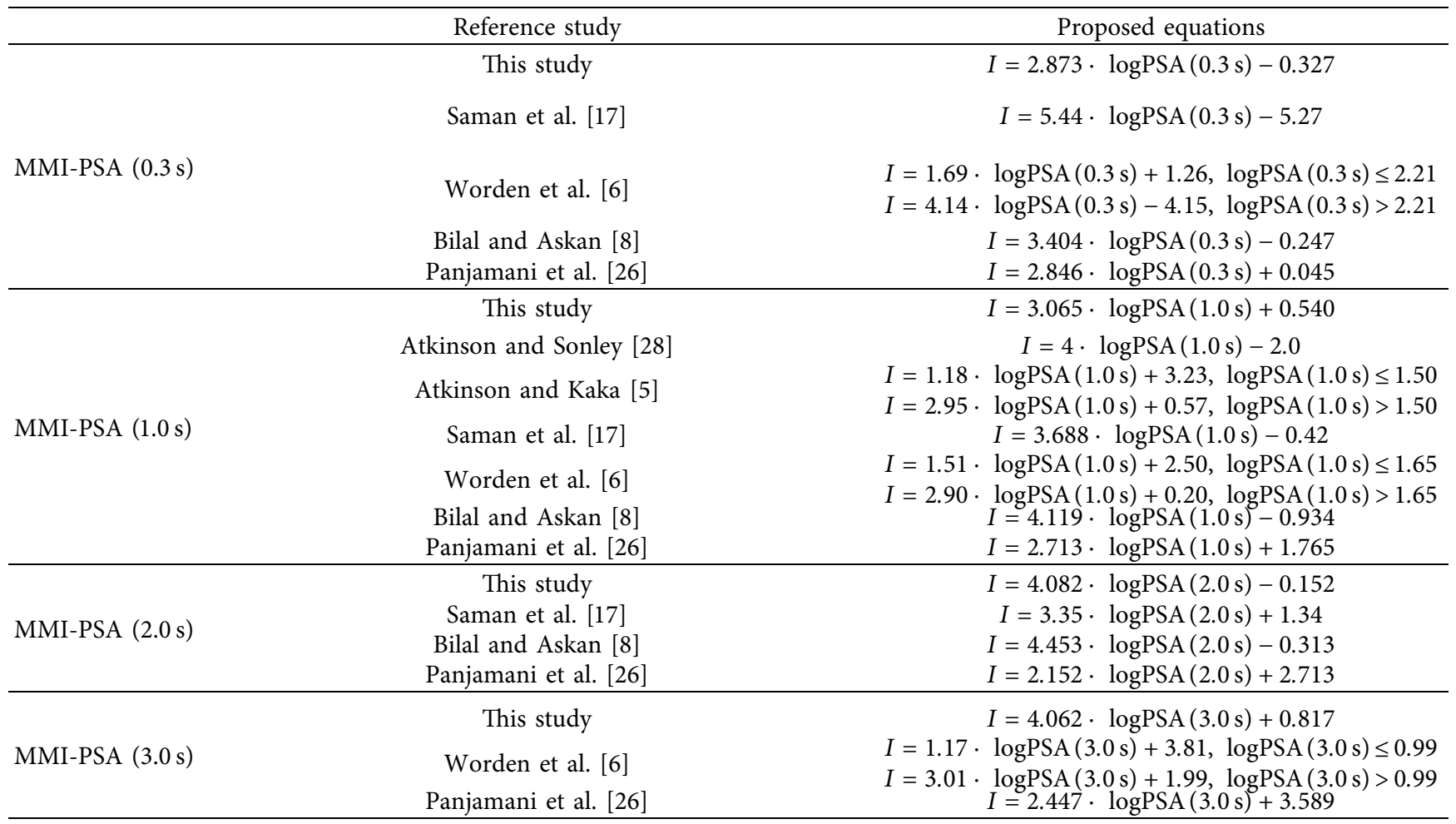
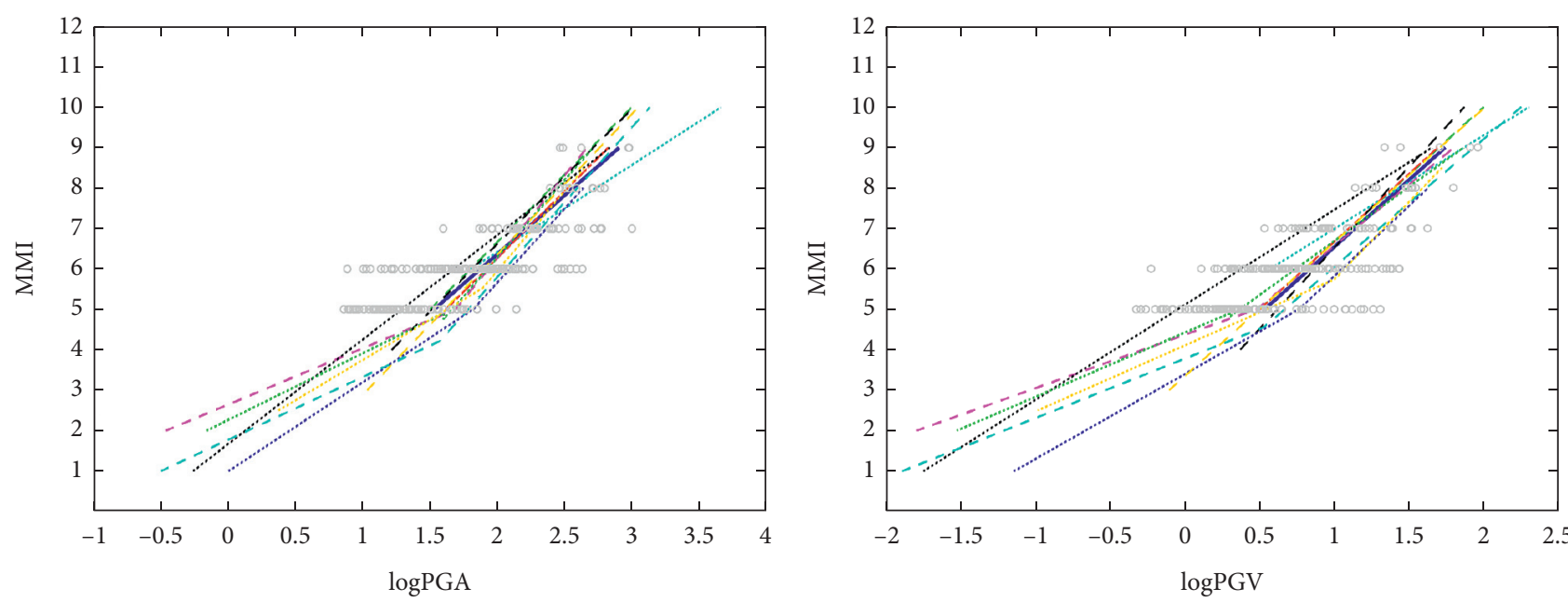

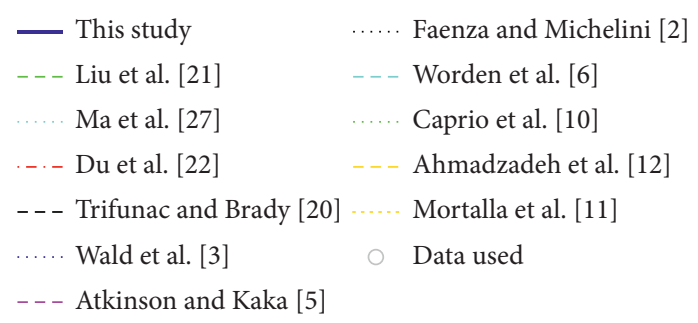

(a)

\begin{tabular}{|c|c|}
\hline — This study & ...... Faenza and Michelini [2] \\
\hline - - - Liu et al. [21] & -- - Worden et al. [6] \\
\hline Ma et al. [27] & Caprio et al. [10] \\
\hline$\cdot \ldots-$ Du et al. [22] & - - Ahmadzadeh et al. [12] \\
\hline - - - Trifunac and Brady [20] & Mortalla et al. [11] \\
\hline Wald et al. [3] & Data used \\
\hline Atkinson and Kaka [5] & \\
\hline
\end{tabular}

(b)

FIgURE 18: Comparison of GMICEs obtained in this study with similar equations from previous studies. (a) MMI-PGA. (b) MMI-PGV. 


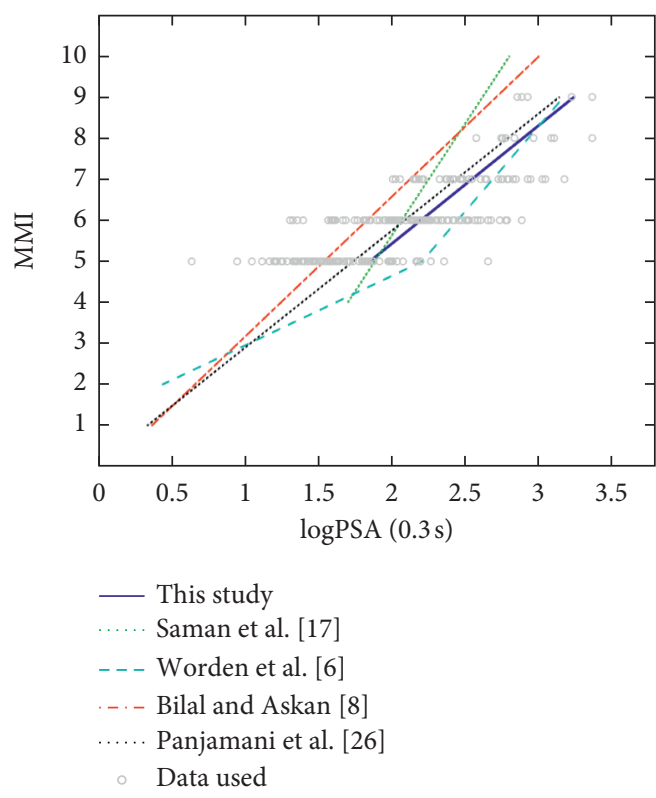

(a)

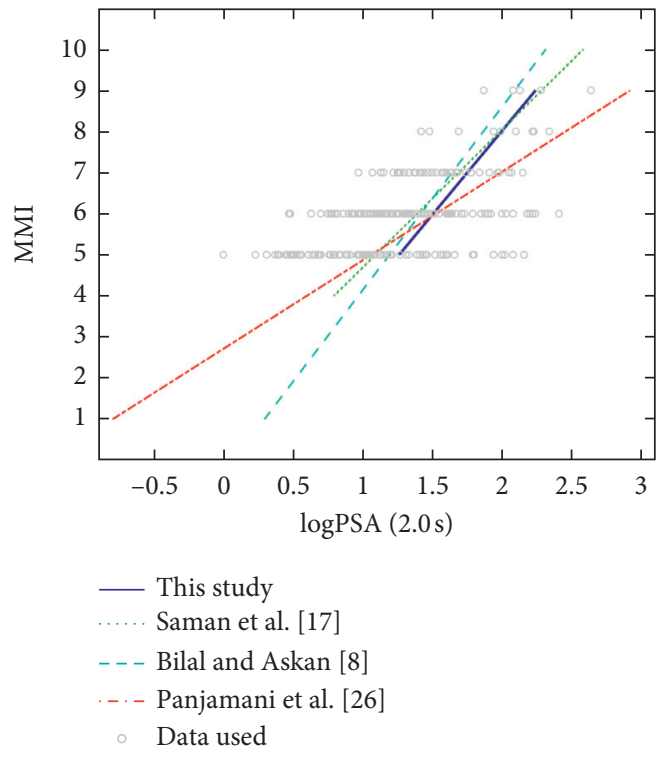

(c)

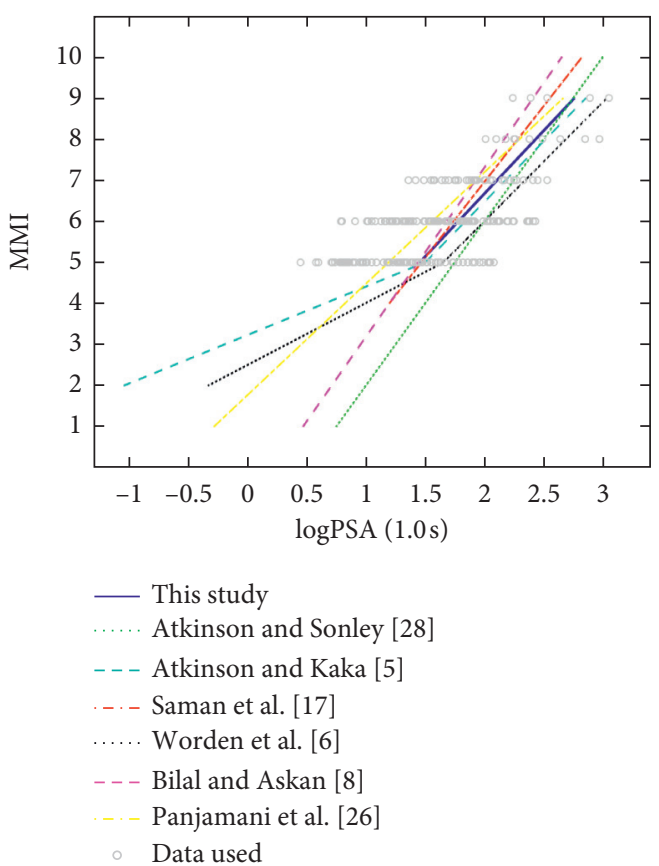

(b)

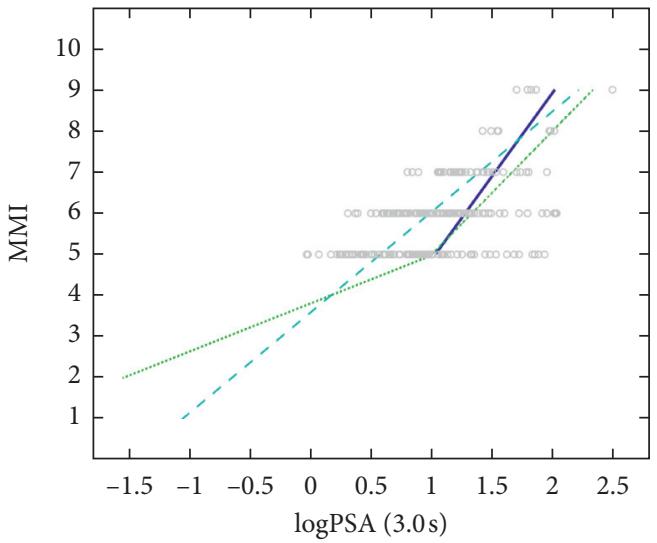

— This study

Worden et al. [6]

- - Panjamani et al. [26]

Data used

(d)

FIGURE 19: Comparison of GMICEs obtained in this study with similar equations from previous studies. (a) MMI-PSA (0.3 s). (b) MMI-PSA $(1.0 \mathrm{~s})$. (c) MMI-PSA (2.0 s). (d) MMI-PSA (3.0 s).

for PSA at present, we cannot get the regional correction factor of PSA for China in our study.

\section{Conclusion}

In this study, we use the strong motion records and seismic intensity data from 11 moderate-to-strong earthquakes in the mainland of China since 2008 and develop new conversion equations between MMI and PGA, PGV, PSA $(0.3 \mathrm{~s})$, PSA (1.0 s), PSA $(2.0 \mathrm{~s})$, and PSA $(3.0 \mathrm{~s})$. Unlike earlier studies in China (e.g., Liu et al. [21] and Ma et al. [27]), we elect to employ orthogonal regression and obtain the reversible relationships, which provide a stable conversion from ground motion to MMI or MMI to ground motion. It is believed that these new GMICEs proposed herein can be used in the future whenever necessary in China, particularly for preparing intensity maps, earthquake disaster and loss assessment, and other engineering applications.

We analyze the effects of the moment magnitude, hypocentral distance, and hypocentral depth on the residuals of conversion equations. By introducing a magnitude-distancedepth correction term, we obtain the improved relationships 
and remove the trends in residuals. It should be noted that $\mathrm{Vs}_{30}$, a factor characterizing the site conditions at the locations of interest, is also a potential independent variable in the conversion equations. However, as of now, there are numerous strong motion stations in China without detailed information on local site conditions. Therefore, we do not include a site correction term in our improved conversion relationships.

The proposed conversion equations are also compared with similar relationships from previous studies. These comparisons confirm that such relationships should be regionally dependent. Since the limited dataset used in this study mainly comes from the central and western regions of China, the conclusions in this paper are only applicable to these regions. An alternative approach is also proposed with a regional correction factor for China, suitable for the global relationships proposed by Caprio et al. [10]. This makes the regional characteristics of China comparable to other regions in the globe having the global relationships as reference.

It is also worth noting that the GMICEs in the present study should not be used beyond the PGM and MMI ranges indicated in Tables 1 and 2 (MMI range between V to IX, Mw range between 5.9 and 7.9, and hypocentral distance range covering 11.2-640.5 km), and PGM data used to develop the equations correspond to the maximum of the two horizontal components. In the future, similar studies need to be conducted with more seismic records and intensity data to further optimize and improve the GMICEs for China.

\section{Data Availability}

The strong motion records used in this study were provided by the China Strong Motion Network Center. The macroseismic intensity dataset, including the intensity maps and post-earthquake disaster investigation reports, was acquired from the provincial seismological bureaus operating under the China Earthquake Administration.

\section{Conflicts of Interest}

The authors declare that they have no conflicts of interest.

\section{Acknowledgments}

This study was supported by Basic Scientific Research Fund of Science and Technology Innovation Base of Lanzhou, Institute of Earthquake Forecasting, China Earthquake Administration (grant no. 2019IESLZ06). The authors would like to thank the China Strong Motion Network Center for providing strong motion records and the provincial seismological bureaus operating under the China Earthquake Administration for providing the isoseismal maps and damage reports of the past earthquakes.

\section{References}

[1] Y. X. Hu, Earthquake Engineering, Seismological Press, Beijing, China, 2006.

[2] L. Faenza and A. Michelini, "Regression analysis of MCS intensity and ground motion parameters in Italy and its application in ShakeMap," Geophysical Journal International, vol. 180, no. 3, pp. 1138-1152, 2010.

[3] D. J. Wald, V. Quitoriano, T. H. Heaton, and H. Kanamori, "Relationships between peak ground acceleration, peak ground velocity, and modified Mercalli intensity in California," Earthquake Spectra, vol. 15, no. 3, pp. 557-564, 1999.

[4] S. I. Kaka and G. M. Atkinson, "Relationships between instrumental ground-motion parameters and modified Mercalli intensity in eastern North America," Bulletin of the Seismological Society of America, vol. 94, no. 5, pp. 1728-1736, 2004.

[5] G. M. Atkinson and S. I. Kaka, "Relationships between felt intensity and instrumental ground motion in the central United States and California," Bulletin of the Seismological Society of America, vol. 97, no. 2, pp. 497-510, 2007.

[6] C. B. Worden, M. C. Gerstenberger, D. A. Rhoades, and D. J. Wald, "Probabilistic relationships between groundmotion parameters and modified Mercalli intensity in California," Bulletin of the Seismological Society of America, vol. 102, no. 1, pp. 204-221, 2012.

[7] V. Y. Sokolov, "Seismic intensity and Fourier acceleration spectra: revised relationship," Earthquake Spectra, vol. 18, no. 1, pp. 161-187, 2002.

[8] M. Bilal and A. Askan, "Relationships between felt intensity and recorded ground-motion parameters for Turkey," Bulletin of the Seismological Society of America, vol. 104, no. 1, pp. 484-496, 2014.

[9] Y.-M. Wu, T. L. Teng, T. C. Shin, and N. C. Hsiao, "Relationship between peak ground acceleration, peak ground velocity, and intensity in Taiwan," Bulletin of the Seismological Society of America, vol. 93, no. 1, pp. 386-396, 2003.

[10] M. Caprio, B. Tarigan, C. B. Worden, S. Wiemer, and D. J. Wald, "Ground motion to intensity conversion equations (GMICEs): a global relationship and evaluation of regional dependency," Bulletin of the Seismological Society of America, vol. 105, no. 12, pp. 1-21, 2015.

[11] J. M. Mortalla, T. Godes, D. A. Rhoades, S. Canessa, and M. C. Gerstenberger, "New ground motion to intensity conversion equations (GMICEs) for New Zealand," Seismological Research Letters, vol. 92, no. 1, pp. 448-459, 2021.

[12] S. Ahmadzadeh, G. J. Doloei, and H. Zafarani, "Ground motion to intensity conversion equations for Iran," Pure and Applied Geophysics, vol. 177, no. 11, pp. 5435-5449, 2020.

[13] B. Gutenberg and C. F. Richter, "Earthquake magnitude, intensity, energy, and acceleration," Bulletin of the Seismological Society of America, vol. 46, no. 2, pp. 105-145, 1956.

[14] J. Hershberger, "A comparison of earthquake accelerations with intensity ratings*," Bulletin of the Seismological Society of America, vol. 46, no. 4, pp. 317-320, 1956.

[15] E. L. Krinitzsky and F. K. Chang, "Intensity-related earthquake ground motions," Environmental and Engineering Geoscience, vol. xxv, no. 4, pp. 425-435, 1988.

[16] G. F. Panza, F. Vaccari, and R. Cazzaro, "Correlation between macroseismic intensities and seismic ground motion parameters," Annali di Geofisica, vol. 15, pp. 1371-1382, 1997.

[17] Y. S. Saman, H. H. Tsang, and T. K. L. Nelson, "Conversion between peak ground motion parameters and modified Mercalli intensity Values," Journal of Earthquake Engineering, vol. 15, pp. 1138-1155, 2011.

[18] R. Spence, A. Coburn, and A. Pomonis, "Correlation of ground motion with building damage: the definition of a new damage-based seismic intensity scale," in Proceedings of the Tenth World Conference on Earthquake Engineering, vol. 1, pp. 551-556, Madrid, Spain, July 1992. 
[19] J. Boatwright, K. Thywissen, and L. C. Seekins, "Correlation of ground motion and intensity for the 17 January 1994 Northridge, California, earthquake," Bulletin of the Seismological Society of America, vol. 91, no. 4, pp. 739-752, 2001.

[20] M. D. Trifunac and A. G. Brady, "On the correlation of seismic intensity scales with the peaks of recorded strong ground motion," Bulletin of the Seismological Society of America, vol. 65, no. 1, pp. 139-162, 1975.

[21] H. X. Liu, R. Lu, and D. Chen, "A proposal of revised china's seismic intensity," The Selection Of Earthquake Engineering Paper From Huixian Liu, Institute of Engineering Mechanics, China Earthquake Administration, Harbin, China, 1980.

[22] K. Du, B. Ding, H. Luo, and J. Sun, "Relationship between peak ground acceleration, peak ground velocity, and macroseismic intensity in western China," Bulletin of the Seismological Society of America, vol. 109, no. 1, pp. 284-297, 2018.

[23] H. Y. Yu, B. F. Zhou, W. X. Jiang et al., "Data processing and preliminary analysis of strong motion records from the Ms7.0 Lushan, China earthquake," Applied Mechanics and Materials, vol. 580-583, pp. 1528-1532, 2014.

[24] H. Y. Yu, W. X. Ding, M. Chen et al., Statistical Interpretation of Data: Detection and Treatment of Outliers in the Normal Sample (GB/T4883-2008), Standards Press of China, Beijing, China, 2008.

[25] W. E. Deming, Statistical Adjustment of Data, Wiley, Newyork, America, 1943.

[26] A. Panjamani, K. Bajaj, S. S. R. Moustafa, and N. S. N. Al-Arifi, "Relationship between intensity and recorded ground-motion and spectral parameters for the himalayan region," Bulletin of the Seismological Society of America, vol. 106, no. 4, pp. 1672-1689, 2016.

[27] Q. Ma, S. L. Li, S. Y. Li, and D. W. Tao, "The correlation of ground motion parameters with seismic intensity," Earthquake Engineering and Engineering Dynamics, vol. 34, no. 4, pp. 83-92, 2014.

[28] G. M. Atkinson and E. Sonley, "Empirical relationships between modified Mercalli intensity and response spectra," Bulletin of the Seismological Society of America, vol. 90, no. 2, pp. 537-544, 2000. 